\title{
Horizontal Cells in the Cone-dominated Tree Shrew Retina: Morphology, Photoreceptor Contacts, and Topographical Distribution
}

\author{
Brigitte Müller and Leo Peichl \\ Max-Planck-Institut für Hirnforschung, D-W-6000 Frankfurt/M. 71, Germany
}

While most mammalian retinas are rod dominated, in the tree shrew retina $95 \%$ of the photoreceptors are cones. We studied tree shrew horizontal cells to look for features associated with this unusual photoreceptor arrangement. The morphology of horizontal cells was revealed by intracellular injections of Lucifer yellow, and their photoreceptor contacts were assessed by light and electron microscopy. Horizontal cell topography was studied in material stained with a neurofilament antibody and with toluidine blue.

The tree shrew has two types of horizontal cell that are basically the same as A- and B-type horizontal cells of other mammals. All the photoreceptor contacts of the larger, axonless, A-type cell and the dendritic contacts of the smaller, axon-bearing, B-type cell are with cones. Both types contact nearly all the cones in their dendritic field and both types synapse with both red and blue cones. There is no anatomical evidence for chromatic selectivity. The sparsely branched B-type horizontal cell axon probably contacts rods as in other mammals. The unusual features of the A-type cell are the profuse dendritic terminal arborizations and the large dendritic field size. These features may be related to the abundance of cones but do not justify the conclusion for a special type of horizontal cell as has previously been supposed.

Both types of horizontal cell have a central-peripheral density gradient; at any location B-type cells are up to three times as numerous as A-type cells. There are detailed features of the distributions that differ from those of other mammalian horizontal cells. The density maximum of B-type cells is in inferior retina and roughly coincides with that of the cones; the A-type maximum is located more superiorly. Neither maximum is colocalized with the ganglion cell peak in the central area. The mosaic of B-type cells is much more regular than that of A-type cells.

[Key words: Tupaia retina, horizontal cells, color vision, outer plexiform layer, Lucifer yellow, immunocytochemistry]

\footnotetext{
Received Dec. 21, 1992; accepted Mar. 1, 1993.

We thank B. B. Boycott and $H$. Wässle for helpful discussions of the project and constructive criticism of the manuscript. The excellent technical assistance of H. Ahmed, F. Boji, W. Hofer, and G.-S. Nam is gratefully acknowledged. This study was supported by a grant from the Deutsche Forschungsgemeinschaft (DFGSFB 45/C7).

Correspondence should be addressed to Dr. Brigitte Müller, Zentrum der Morphologie, Abteilung Neurobiologie, J. W. Goethe-Universität, Theodor-Stern-Kai 7, D-W-6000 Frankfurt/M. 71, Germany.

Copyright (C) 1993 Society for Neuroscience $0270-6474 / 93 / 133628-19 \$ 05.00 / 0$
}

Horizontal cells are retinal interneurons that modulate the information flow from the photoreceptors to the bipolar cells in the outer plexiform layer (OPL). Mammalian retinas generally have two morphological types of horizontal cell (reviewed by Gallego, 1986; Boycott et al., 1987; Boycott, 1988). In most mammals they are termed A- and B-type; for primates the terms HI and HII have been introduced (Kolb et al., 1980). At all retinal locations the A-type cell has a larger dendritic tree than the B-type cell. The dendrites of both have many clustered terminals that are the contacts with individual cones. The B-type cell has an axon with an axon terminal system exclusively connected to rods.

Most mammalian retinas so far studied have a high proportion of rods; only up to about $10 \%$ of the photoreceptors are cones. In the diurnal tree shrew Tupaia belangeri $95 \%$ of the photoreceptors are cones (Müller and Peichl, 1989). Mariani (1985) showed that the tree shrew also has two distinct types of horizontal cell. Because the larger type has several processes that end in profuse terminal arborizations, he concluded that this cell is "multiaxonal" and represents a special type not present in other mammals. We have studied the morphology and synaptic connections of tree shrew horizontal cells by light and electron microscopy (LM, EM) to see whether they are genuinely unusual types of cells associated with a specialized retina, or whether they are basically similar to the A- and B-type cells of other mammals but having modifications related to the preponderance of cones.

We were particularly interested to see whether tree shrew horizontal cells are cone selective and thus potentially color coded. A- and B-type horizontal cells in rabbit and cat contact nearly all cones within their dendritic field, thus precluding a selectivity for specific cone types (Wässle et al., 1978a; Raviola and Dacheux, 1990). In primates the situation is controversial. In monkeys there is clear quantitative evidence that the HI and HII horizontal cells contact all cones and that as a population neither horizontal cell type is chromatically selective (Boycott et al., 1987; Wässle et al., 1989). Others have given qualitative evidence for human horizontal cell types showing preferences for or avoiding certain cones and thus claim color coding (Kolb, 1991; Kolb and Ahnelt, 1992; Kolb et al., 1992). Thus, in addition to studying claims for special horizontal cell types in tree shrew, it seemed important to study horizontal cell connectivity in an "all-cone" retina. The tree shrew is a dichromat with bluesensitive and red-sensitive cones (Petry and Hárosi, 1990). They can be distinguished by histological and immunohistochemical methods (Müller and Peichl, 1989; Müller et al., 1989). Thus, a direct analysis of the cone types connected with the horizontal cells is possible. 
Parts of this study have been published in abstract form (Peichl and Müller, 1991).

\section{Materials and Methods}

Animals. The retinas of adult tree shrews (Tupaia belangeri) of either gender were used. All animals were obtained from our institute's breeding colony. The animals were killed with an overdose of pentobarbital, given intraperitoneally. Twenty-one eyes of 15 animals were used for Lucifer yellow injections; six eyes of six animals for neurobiotin injections. For neurofilament (NF) immunocytochemistry, six eyes of six animals were used.

Preparation of retinas for dye injections. The eye was enucleated and cut open around the ora serrata, and the anterior part with lens and vitreous was removed. The posterior eyecup with the retina attached was transferred to cold $\left(4^{\circ} \mathrm{C}\right)$ physiological medium containing $137 \mathrm{mM}$ $\mathrm{NaCl}, 5 \mathrm{~mm} \mathrm{KCl}, 2 \mathrm{~mm} \mathrm{CaCl}, 1 \mathrm{~mm} \mathrm{Na} \mathrm{HPO}_{4}, 1 \mathrm{~mm} \mathrm{MgSO}, 22 \mathrm{~mm}$ glucose, and $10 \mathrm{~mm}$ HEPES in distilled water, $\mathrm{pH}$ 7.4. The retina was dissected from the eyecup and any adhering pigment epithelium. A drawing of the retina and its main blood vessels was made before cutting the tissue into manageable pieces, so that the retinal positions of injected cells could later be determined by reconstruction. In some retinal pieces, the outer and inner segments of the photoreceptors were also brushed off to facilitate penetration of the micropipette into the horizontal cell layer from the photoreceptor side. The tissue was left in the physiological medium for $10 \mathrm{~min}$, so that severed or ruptured membranes could seal.

Intracellular injection of Lucifer yellow. For Lucifer yellow (LY) injections retinal pieces were fixed in $4 \%$ paraformaldehyde (PA) in phosphate buffer (PB; $0.1 \mathrm{M}, \mathrm{pH} 7.4$ ) for $30 \mathrm{~min}$ at $4^{\circ} \mathrm{C}$, or in $2 \% \mathrm{PA}$ in $\mathrm{PB}$ for $25 \mathrm{~min}$ at room temperature. After fixation the tissue could be kept in $\mathrm{PB}$ at $4^{\circ} \mathrm{C}$ for up to $2 \mathrm{~d}$. Fixed pieces of retina were floated onto a slide, photoreceptor side up, in PB and held in place by a grid of nylon threads fixed on a frame of platinum-iridium. The slide was transferred to a Pctri dish containing $0.1 \mathrm{M} \mathrm{PB}$, and the dish was placed on a fixcdstage microscope (ACM, Zeiss, Oberkochen, Germany). Horizontal cells were injected intracellularly with LY according to the protocol of Peichl et al. (1987a), which generally follows the original protocol of Tauchi and Masland (1984). A negative constant current of 1-2 $\mathrm{nA}$ for 8-15 min was necessary to fill all processes of impaled cells. Within $12 \mathrm{hr}$, up to 50 cells could be successfully filled per retina.

After injection the retina was washed in PB for several hours, postfixed in 4\% PA in PB for $1 \mathrm{hr}$, washed in PB, placed on a slide, photoreceptor side up, and coverslipped in PB. Retinal pieces not intended for photoconversion were coverslipped in glycerol. Focal series of filled cells were photographed on black and white film (Kodak Tri-X-pan) with a $16 \times$ or $25 \times$ objective (Neofluar, Zeiss) and the cells were reconstructed by tracing the enlarged negatives. After photography, some of the material was processed for either photoconversion or for immunohistochemical staining as described below. A total of about 400 horizontal cells were injected with $L Y$ at various retinal locations without prelabeling the somata. Of these, $126 \mathrm{~A}$-type and $142 \mathrm{~B}$-type horizontal cells were analyzed in detail.

Intracellular injections of Neurobiotin. The handling of retinas and technique of Neurobiotin injections were as for LY injections, but without fixation. Pieces of living retina in the injection dish were continuously superfused with physiological medium of the following composition (in mM): $\mathrm{NaCl}, 110 ; \mathrm{KCl}, 5 ; \mathrm{CaCl}_{2}, 2 ; \mathrm{Na}_{2} \mathrm{HPO}_{4}, 1 ; \mathrm{NaHCO}_{3}, 25$; $\mathrm{MgSO}_{4}, 1$; HEPES, 10 ; and glucose, 15.14. This solution was continuously oxygenized with a mixture of $95 \% \mathrm{O}_{2}$ and $5 \% \mathrm{CO}_{2}$, thus kecping the $\mathrm{pH}$ at 7.4. The injection micropipettes contained $1 \% \mathrm{LY}$ and $5 \%$ $N$-(aminoethyl)biotinamide hydrochloride (Neurobiotin, Vector Laboratories, Burlingame, $\mathrm{CA}$ ) in $0.1 \mathrm{M}$ Tris $\mathrm{HCl}$ buffer. A short initial $\mathrm{LY}$ injection was applied to determine whether the impaled cell was a horizontal cell. Then, the neurobiotin tracer was injected with depolarizing continuous currents of 1-2 nA for about $10 \mathrm{~min}$. Finally, a second short LY injection served to confirm that the pipette was still in the same cell. After injection the retinal pieces were processed according to the protocol of Vaney (1991). Briefly, the tissue was equilibrated in the physiological medium for about $1 \mathrm{hr}$ and then fixed in 4\% PA in PB for $1 \mathrm{hr}$. After rinsing it was incubated in $0.5 \%$ Triton X-100 in PB for $1 \mathrm{hr}$, reacted with 1:100 streptavidin-biotinylated horseradish peroxidase complex, and then visualized with $3^{\prime}, 3$-diaminobenzidine (DAB) as in the immunohistochemical procedures. Finally, the tissue was coverslipped in glycerol and analyzed light microscopically.
Photoconversion of Lucifer yellow. For electron microscopy, LY was transformed into an electron-dense product by a photooxidative process according to the protocol of Maranto (1982) and Sandell and Masland (1988). Briefly, pieces of tissue containing the I.Y-filled cells were incubated in a solution of DAB $(1.5 \mathrm{mg} / \mathrm{ml}$ in $0.1 \mathrm{M}$ Tris $\mathrm{HCl}, \mathrm{pH} 8.2)$ and potassium cyanide $(1 \mathrm{mg} / \mathrm{ml})$. The injected cells were illuminated on a microscope stage using a $16 \times / 0.40$ objective (Neofluar, Zeiss) and blue $(400-440 \mathrm{~nm})$ light. The process was performed under visual control and stopped after 15-20 min when the injected cell did not become darker in comparison to the background. Subsequently, the retinal pieces were washed and coverslipped in PB.

The retinal pieces intended for light microscopic evaluation were either coverslipped in glycerol or mounted on gelatinized slides, dehydrated, and coverslipped in Permount (Fisher, Fair Lawn, NJ). Detailed drawings of the photoconverted horizontal cells were made with a high-power oil-immersion objective $(100 \times / 1.25$ Plan $)$ and a Zeiss drawing tube. The dendritic field area was analyzed with a semiautomatic image analyzing system (ASM, Leitz, Wetzlar, Germany). For electron microscopy, small areas containing photoconverted cells were cut out of the retinal pieces, processed for routine electron microscopy, and cmbedded in Epon as described in Müller and Peichl (1991a,b). Tangential or transverse ultrathin sections $(\sim 70 \mathrm{~nm}$ silver-gold interference colors) were cut on an ultramicrotome, mounted on single-slot grids coated with Formvar film, and occasionally stained with lead citrate.

Glycerol caused an areal shrinkage varying between $9 \%$ and $33 \%$ depending on the size and retinal location of the tissue. Dehydration caused an areal shrinkage of $30-40 \%$. All morphometric data taken from injected material are corrected for shrinkage.

Lucifer yellow immunocytochemistry. An antibody against LY raised in rabbit was used to label LY-injected cells permanently for light microscopy. The LY antibody was a kind gift of Dr. Tom Ruigrok (Erasmus University, Rotterdam) and was raised in collaboration with Ruud Buys (Netherland Institute for Brain Research) and Floris Wouterlood (Anatomical Department of Vrije Universiteit, Amsterdam). Immunoreactivity against LY was demonstrated on retinal whole-mount pieces by the avidin-biotin peroxidase complex $(\mathrm{ABC})$ according to Hsu et al. (1981). Incubation media and dilution of the first antibody $(1: 3000)$ were adopted from the protocol of Wouterlood et al. (1990). The wholemount pieces were processed as described in detail by Müller and Peichl (1991a,b), except that all incubation steps were done at room temperature for half the times given there. The secondary antibody was a biotinylated goat anti-rabbit IgG (B-7389, Sigma, St. Louis, MO), diluted 1:50. Omission of the primary antibody from incubation steps resulted in no staining.

$S$-antigen immunocytochemistry. Lucifer yellow immunolabeling was followed by S-antigen immunocytochemistry. A polyclonal antibody against an S-antigen epitope raised in rabbit was used to label the bluesensitive cones (Müller et al., 1989). The antibody was raised by Dr. Igal Gery and coworkers (NIH, Bethesda, MD) and kindly provided by Prof. H.-W. Korf (Universität Frankfurt/M., Germany). All incubation steps were carried out at room temperature in $0.1 \mathrm{~m}$ phosphate buffer (pH 7.4). Incubation solutions were according to the protocol of Müller and Peichl (1991a,b). Both the first antibody and the second antibody, an FITC-conjugated anti-rabbit IgG (Sigma), were diluted 1:100. After rinsing in PB the tissue was coverslipped in glycerol. In areas containing LY-injected horizontal cells, the labeled photoreceptor pattern was photographed under epifluorescence illumination. Then, the overall photoreceptor pattern and the LY-immunoreactive (LY-IR) horizontal cells were photographed with white light and Nomarski optics. The pattern of labeled photoreceptors, the complete photoreceptor pattern, and the LY-IR horizontal cells were reconstructed and superimposed from tracings of the enlarged negatives.

Neurofilament immunocytochemistry. The posterior eyecup with the retina attached was immersed in $4 \% \mathrm{PA}$ in $\mathrm{PB}$ for $2 \mathrm{hr}$ at $4^{\circ} \mathrm{C}$. After fixation, the retina was removed from the eyecup and pretreated for sectioning and immunocytochemistry as described in detail by Müller and Peichl (1991a,b). Briefly, the tissue was cryoprotected by immersion in a series of $10 \%, 20 \%$, and $30 \%$ sucrose overnight and repeatedly shock-frozen and thawed in liquid nitrogen to improve penetration of antibodies. Immunocytochemistry was performed both on retinal wholemounts and on frozen sections. The retinas were sectioned either parallel to the vitreal surface (horizontal sections) or perpendicular to it (vertical sections). A commercial mouse monoclonal antibody against the 70 $\mathrm{kDa}$ and $200 \mathrm{kDa}$ neurofilament subunits was used (clone $2 \mathrm{~F} 11$, cat. 

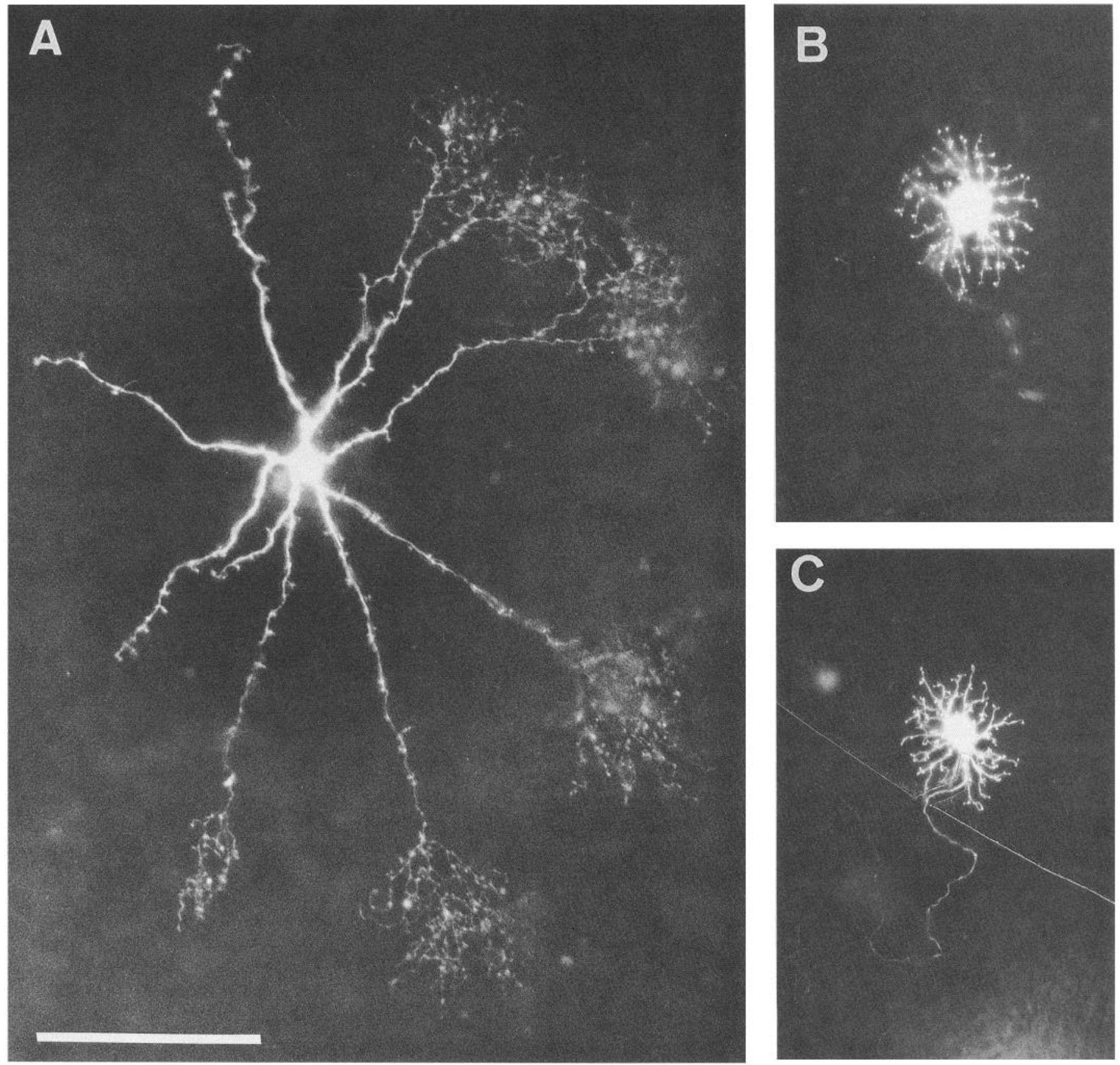

Figure 1. Tree shrew horizontal cells, injected with LY, in flat view. A, A-type cell with a large, sparsely branched dendritic tree. Several dendrites end in profuse arborizations. $B$, Dendritic tree of a B-type cell. The focus in on the regular pattern of the terminal aggregates (sites of cone contacts). Soma, main dendrites, and axon (bottom) are out of focus. $C$, Another B-type cell. The montage of two focal levels shows the dendritic tree and axon, which are on slightly different levels. All micrographs are at the same magnification to illustrate the size difference between A-and B-type cells. Scale bar, $100 \mu \mathrm{m}$.

no. MON 3004, Sanbio, Uden, The Netherlands). Immunoreactivity was demonstrated by the $\mathrm{ABC}$ method; the primary antibody was diluted 1:10-1:50. For details of tissue processing see Müller and Peichl (1991a,b).

Quantitative procedures. Density maps of neurofilament-immunoreactive horizontal cells were obtained from a series of horizontal 40 $\mu \mathrm{m}$ sections by the procedure described in Müller and Peichl (1989, 1991a,b). Because the tree shrew has a thick optic nerve fiber layer, penetration of the antibodies in unsectioned tissue was not sufficiently consistent across the retina for a complete topographic evaluation. Sample fields were analyzed with a $40 \times / 1.0$ oil-immersion objective (Zeiss Planapo; sample field size, $250 \times 250 \mu \mathrm{m}$ ); 245 sample fields were used for the density map shown in Figure $15 \mathrm{~A}$. Shrinkage was assessed by comparing retinal size before histological treatment with that after mounting, and areal shrinkage was about $7 \%$. Density values given in Results are not corrected for shrinkage.

Density maps of B-type horizontal cells were obtained from a series of horizontal $5 \mu \mathrm{m}$ glycol methacrylate sections through the retina, stained with toluidine blue. The detailed photoreceptor distribution of this retina has been published in Müller and Peichl (1989, their Fig. $5 A, D$ ), where the reconstruction of the retina from drawings of tangential sections is also described. Each section was examined, and in each area containing the outermost inner nuclear layer (INL) counts of the A-type and B-type horizontal cells were made. Sample fields were analyzed with 
a $63 \times / 1.25$ oil-immersion objective (Zeiss Neofluar; sample field size, $154 \times 154 \mu \mathrm{m}) ; 121$ sample fields were used for the density map shown in Figure $15 B$. Areal shrinkage was about $3 \%$ and density values given in Results are not corrected for shrinkage.

Terminology. In the tree shrew retina, most cell populations investigated so far have shallow density distributions. The density maxima of the rods and cones are in inferior retina, and not at a central area defined by the ganglion cell density maximum (Müller and Peichl, 1989), and the density maxima of the rod bipolar cells and the dopaminergic amacrine cells are ill defined (Müller and Peichl, 1991a,b). The central area is thus not a convenient reference point, and the terms temporal, nasal, superior, inferior, and central are used here with respect to the optic disk, not with respect to the central area.

\section{Results}

\section{Morphology of B-type and A-type horizontal cells}

LY injection of horizontal cells in the tree shrew retina revealed two types of horizontal cell that correspond to Mariani's (1985) "multiaxonal" and "uniaxonal" horizontal cells. Our LM observations agree with Mariani's description. We shall use the terms A-type for the "multiaxonal" and B-type for the "uniaxonal" type, because our results strongly suggest that tree shrew horizontal cells conform to these basic mammalian types.

B-type horizontal cells of the tree shrew show a straightforward similarity to those of cat and rabbit. Soma diameters vary between 8 and $13 \mu \mathrm{m}$ (mean $\pm \mathrm{SD}, 10 \pm 1.5 \mu \mathrm{m}$ ) with no clear correlation with retinal location. Five to eight short primary dendrites emerge from the soma and branch radially to form a relatively densely branched dendritic tree (Fig. 1B,C). B-type horizontal cells possess a single axon with a few short collaterals and few single terminals. The axon arises from the cell body or one of the dendrites and follows a twisted course in the inner part of the OPL. Along its whole length of at least $300 \mu \mathrm{m}$, the axon has irregularly spaced varicosities. Some of the axons branch once or twice. The low axonal branching density is the only peculiarity of tree shrew B-type cells.

A-type horizontal cells have soma diameters varying between 8 and $14 \mu \mathrm{m}$ (mean $\pm \mathrm{SD}, 11 \pm 1.1 \mu \mathrm{m}$ ), with a tendency toward smaller diameters in central retina and larger diameters in peripheral retina. A-type cells have between three and seven primary dendrites that may bifurcate up to four times (Fig. 1A). Thick primary dendrites (up to $5.5 \mu \mathrm{m}$ in diameter) branch close to the soma into structures that rarely branch further as they radiate outward and taper to about $0.5 \mu \mathrm{m}$ in diameter. At the periphery of this dendritic field some of the dendrites then branch frequently to form bushy arborizations that are unique to the tree shrew (Fig. 1A). Like Mariani (1985), we never found an A-type cell with terminal arborizations on every dendrite.

Do A-type cells really have varying proportions of dendrites with terminal arborizations, or does this asymmetry represent incomplete staining of cells that have a terminal arborization on each dendrite? NF immunostaining revealed the basic dendritic trees of A-type cells (see below and Fig. 12) but not the fine processes of the terminal arborizations, so this material could not be used to resolve the question. In our LY material, we observed that mechanical stress applied to the retinal tissue during preparation seemed to affect the integrity of the A-type horizontal cells; many of the dendrites without terminal arborizations looked distinctly severed. However, many dendrites without terminal arborizations or with only a few short terminal branches did not look damaged or incompletely filled (see Fig. 7), so we assume that not all dendrites have a terminal arborization, and the existing arborizations certainly vary in size.
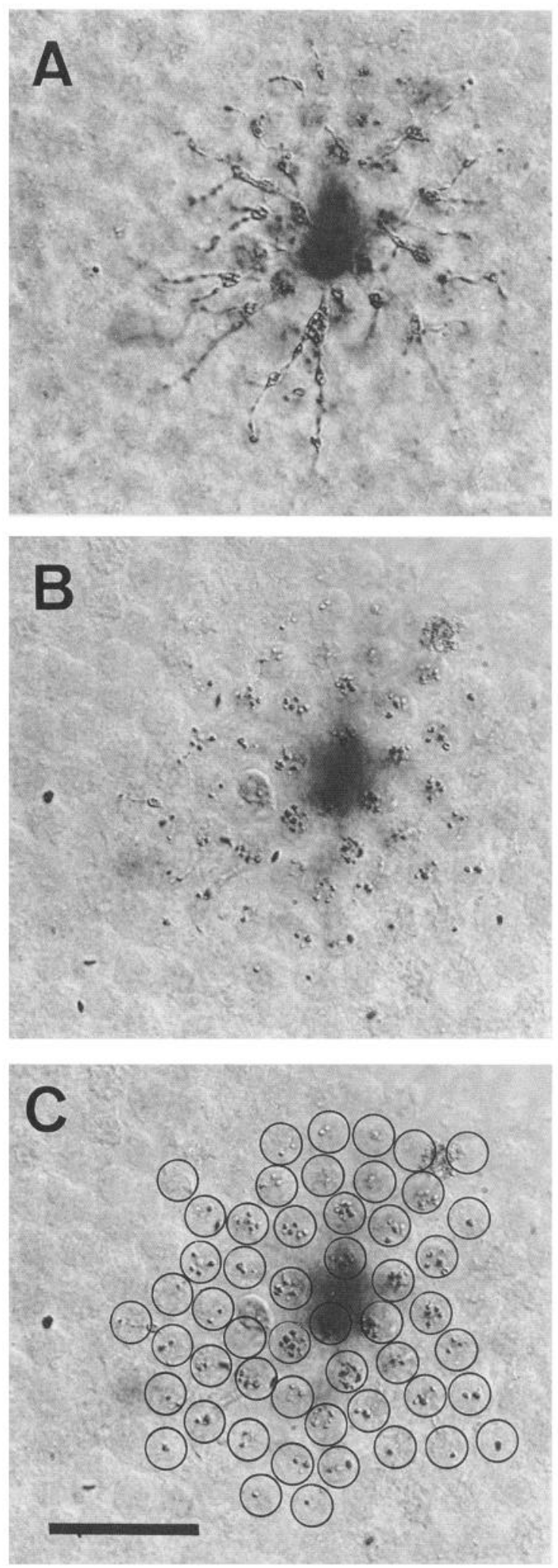

Figure 2. B-type horizontal cell after LY injection and photoconver$\operatorname{sion} . A$, Focus on the main dendrites; the soma is out of focus. $B$. Focus on the dendritic terminal aggregates. The Nomarski optics at the same time reveal the profiles of the unstained cone pedicles. All cone pedicles in the cell's dendritic field contain terminals and thus have contact with the horizontal cell. $C$, Same micrograph as $B$; circles of the approximate pedicle size have been drawn around the pedicles to make identification easier. Scale bar, $25 \mu \mathrm{m}$ for $A-C$. 

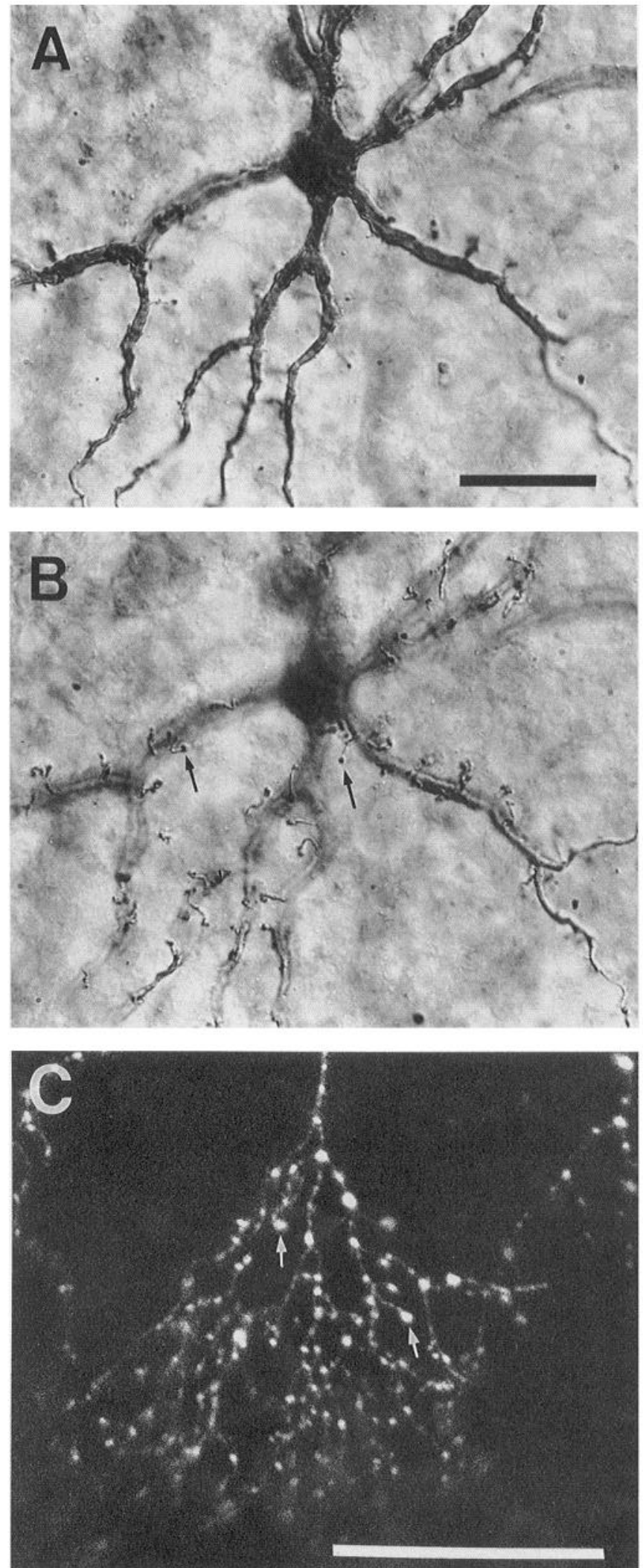

Figure 3. High-power flat views of A-type horizontal cells. A, Focus on the soma and main dendrites of an A-type cell after LY injection and photoconversion. $B$, Same field, focused on the terminals (two are marked by arrows). $C$, Dendritic terminal arborization of another A-type cell after LY injection. Two terminals are marked by arrows. In addition to numerous terminals, varicosities are found along the processes. Scale bars: $A, 50 \mu \mathrm{m}$ for $A$ and $B ; C, 50 \mu \mathrm{m}$.

\section{Photoreceptor contacts}

B-type horizontal cells have clusters of terminals (terminal aggregates) throughout their dendritic tree; these end in the OPL at the level of the cone pedicles (Fig. 2). Terminal aggregates are found at the ends of fine processes arising from the main dendrites; single terminals are often found at dendritic tips. A-type cells possess fine side branches all along their dendrites that end as single spiny terminals or terminal aggregates in the OPL at the level of the cone pedicles (Fig. 3; see also Fig. 8). They are usually 4-8 $\mu \mathrm{m}$ in length; longer processes, up to 18 $\mu \mathrm{m}$ in length, are occasionally found. The spacing between these terminals is $5-8 \mu \mathrm{m}$, depending on retinal location and thus cone density (Fig. $3 B$; see also Fig. 8). The bushy terminal arborizations at the end of dendrites also end in small knob-like terminals or terminal aggregates. Our LY injections reveal a higher density of terminals, on all parts of the A-type cells, than Mariani's (1985) Golgi material.

EM analysis of horizontal and vertical ultrathin sections confirms that B-type dendritic terminal aggregates, as well as A-type terminal aggregates both along the dendrites and on the bushy arborizations, always end in cone pedicles where they form one of the two lateral elements of the triad synapses (Fig. $4 A, B$ ). In only a few instances did we observe that both lateral elements were formed by terminals of the same A-type cell (Fig. 4C). Dendritic terminals of B-type cells or any terminals of A-type cells were never observed to invaginate rod spherules.

The number of terminals per terminal aggregate can be assessed at the LM level (compare Figs. 2, 3) or at the EM level in horizontal sections. Figure 5 shows the number of terminals per aggregate of B-type and A-type horizontal cells. The analyzed terminal aggregates of A-type cells do not include the bushy terminal arborizations. Terminal aggregates of B-type horizontal cells consist of one to eight terminals (mean, 2.9 terminals). The most common aggregate sizes are two or three terminals. Terminal aggregates of A-type horizontal cells consist of one to seven terminals (mean, 2.5 terminals). Single terminals and aggregates with two terminals are most common. The terminal aggregates of the bushy A-type terminal arborizations also consist of one to seven terminals. Here aggregate sizes are rather similar to those of B-type cells; aggregates with two and three terminals are more numerous than single terminals.

Due to their fineness and length, axons of B-type cells were often incompletely or faintly filled, so photoconversion and an EM analysis of the axonal photoreceptor contacts were not feasible. It is, however, very likely that they contact rods (see Discussion).

\section{Horizontal cells contact both types of cone}

Tree shrews are dichromats with $90-96 \%$ red-sensitive cones and $4-10 \%$ blue-sensitive cones, depending on retinal location (Müller and Peichl, 1989; Petry and Hárosi, 1990), so it was of interest to see whether there is any selectivity in the cone connections of the horizontal cells.

B-type horizontal cells. B-type terminal aggregates form a regular pattern and practically all cone pedicles in the central part of a cell's dendritic tree are contacted (Fig. $2 B, C$; see also Fig. 9). In peripheral parts of the dendritic tree sometimes cone pedicles are not reached by terminal aggregates. B-type cells usually contact $93-100 \%$ of cones in their dendritic field, which is between 40 and 80 cones depending on retinal location. With well-stained cells, not more than three cones within the field 

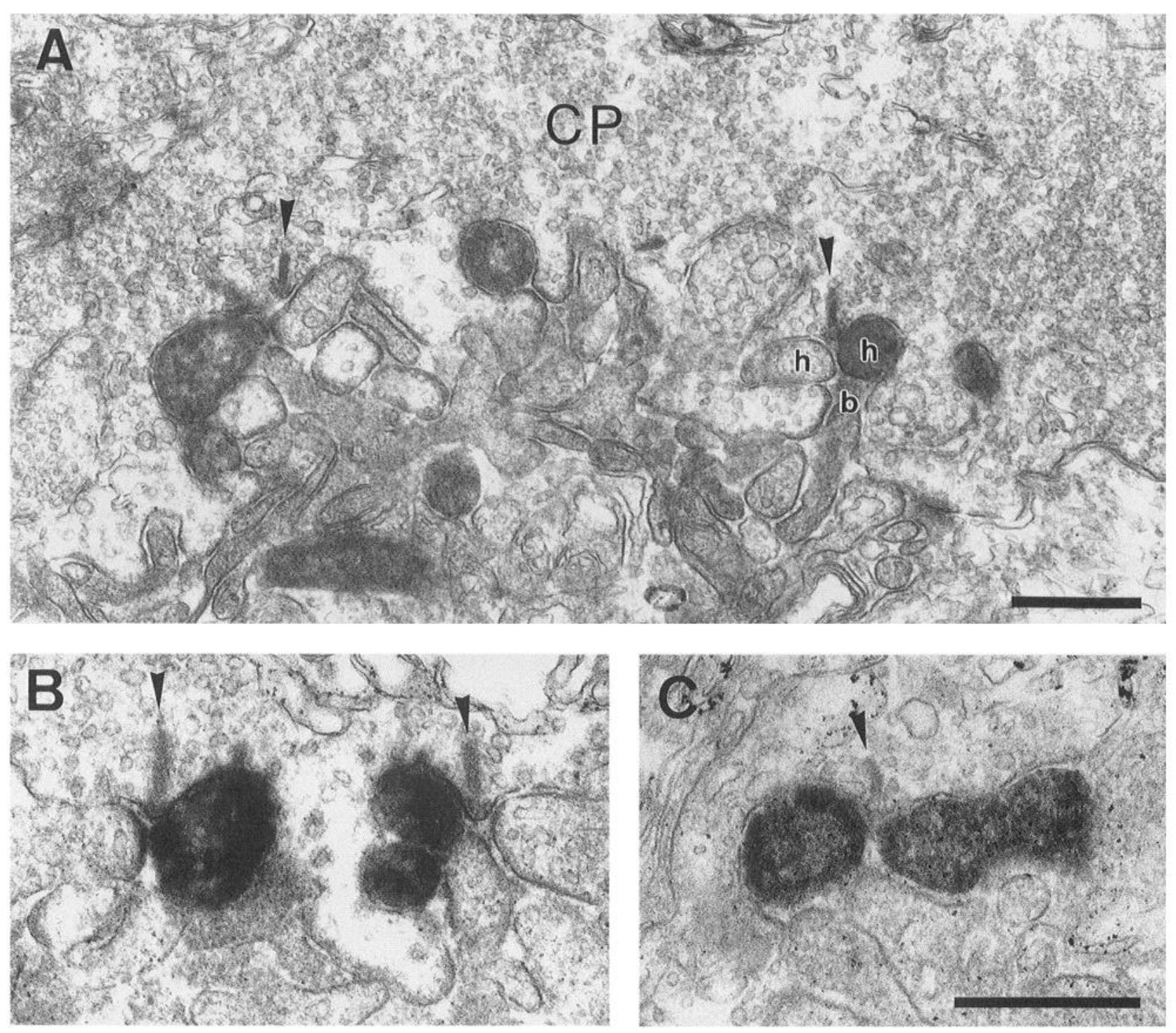

Figure 4. Photoreceptor contacts of horizontal cells. $A$, Electron micrograph of an ultrathin vertical section through a cone pedicle $(C P)$ containing terminals of an LY-injected and photoconverted B-type cell. There are four labeled terminals; two are seen as lateral elements of ribbon triad synapses (arrowheads) in this section. $h$, horizontal cell process; $b$, bipolar cell process. $B, C$, Electron micrographs of similarly identified A-type terminals in cone pedicles. $B$, Usually there is only one process from a cell at any one triad. Here two processes are going to adjacent triads. $C$, More rarely, both lateral elements of a triad synapse come from the same A-type cell. Ribbons are marked by arrowheads. Scale bars: $A, 0.5 \mu$ m; $C, 0.5 \mu \mathrm{m}$ for $B$ and $C$.

were left without contacts; these "missed" cones were not arranged in the regular pattern expected for the blue-sensitive cones in the tree shrew retina (Müller et al., 1989).

To show directly the connectivity between blue-sensitive cones and B-type horizontal cells, a double-label procedure was used in some experiments (Fig. 6). First, LY-injected horizontal cells were immunoreacted with an antibody against LY to obtain a stable opaque staining (Fig. 6A). Second, the blue-sensitive cones were immunohistochemically labeled with an antibody against the S-antigen (Fig. 6B). The S-antigen antibody labels all parts of the blue-sensitive cones including the pedicles. Then it was checked whether the S-antigen-IR photoreceptors within the dendritic field of the injected horizontal cells received horizontal cell terminals. Figure $6 D$ shows the superposition of the cone pattern and the horizontal cell terminals as observed after the double-label procedure. The terminal aggregates of injected horizontal cells do indeed contact the S-antigen-IR, blue-sensitive cones. As there are only two types of cone, all other contacted cones are red sensitive, and hence B-type horizontal cells do not show cone selectivity.

A-type horizontal cells. Because of their sparse dendritic branching, the effective dendritic field of A-type cells outlined in Figure 7 is smaller than the area within the circumference of the dendrites. The effective dendritic field of a horizontal cell is defined as the area that is potentially accessible to terminals (Wässle et al., 1989). Figure 8 shows, for a completely stained A-type dendrite, the isolated pattern of the terminal aggregates and the overlying cone nuclei together with the terminal aggregates. All cones that can be reached by the dendrite or its terminals actually receive contacts. The main dendrite contacts 63 cones; the bushy terminal arborization contacts 94 cones. Overall, the number of cones contacted by A-type cells is extremely large. Excluding the dendritic terminal arborizations, we found over 300 cones contacted per cell. We did not attempt to quan- 
B - type

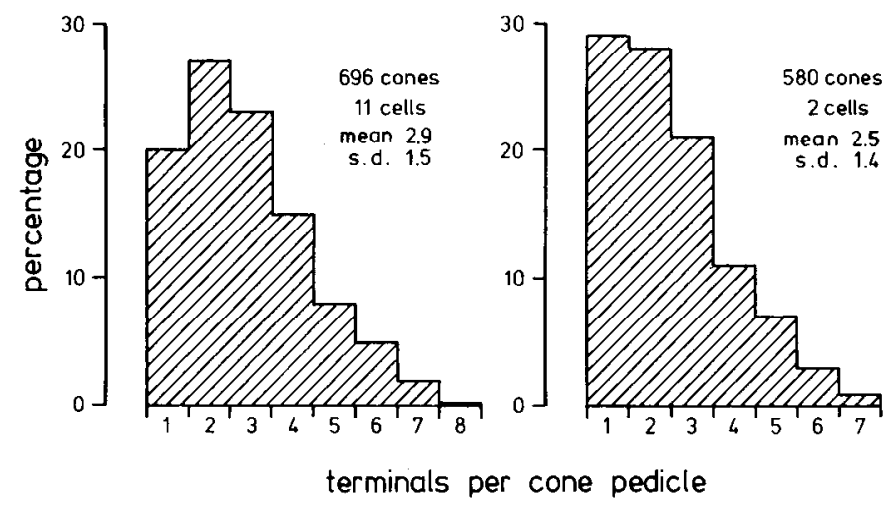

Figure 5. Histograms of the relative frequency of the number of terminals per terminal aggregate. For B-typc cells, data are based on 11 cells contacting 696 cones. For A-type cells, data come from two cells contacting 580 cones; terminals at bushy arborizations are not included. For details, see Results.

tify a cell fully by including all terminal arborizations because it was not certain that all arborizations were fully revealed. However, assuming a cell similar to those in Figurc 7, with four terminal arborizations as in Figure 8 contacting some 90 cones and seven dendrites contacting some 60 cones, an A-type cell may be in contact with a total of $(7 \times 60)+(4 \times 90)=780$ cones. Thus, an individual A-type cell is in contact with between 10 and 20 times more cones than a B-type cell.

From the above observations it appears that A-type cells, like B-type cells, show no cone selectivity. This was shown directly by labeling the blue-sensitive cones immunohistochemically with the S-antigen antibody after injection of LY into A-type horizontal cells. Terminals both along the dendrites and on the bushy arborizations contact the labeled blue-sensitive cones as well as the unlabeled red-sensitive cones.

\section{Dendritic field sizes}

B-type horizontal cells. B-type horizontal cell dendritic fields are approximately circular (Fig. 9). Their dendritic field area increases from central to peripheral retina, but different gradients occur in different retinal sectors. The largest dendritic field areas are located in the periphery of the superior hemiretina. B-type horizontal cells in inferior periphery are smaller than in nasal or temporal peripheral retina. From all directions dendritic field area decreases toward central-inferior retina, as does the number of cones contacted.

Dendritic field areas of B-type horizontal cells ranged from $1250 \mu \mathrm{m}^{2}$ to $4450 \mu \mathrm{m}^{2}$, corresponding to diameters of $40-75$ $\mu \mathrm{m}$, and contained between 40 and 80 terminal aggregates. Figure 9 shows camera lucida drawings of B-type cells from peripheral retina (Fig. 9A) and from central retina (Fig. 9D). The isolated patterns of terminal aggregates are shown in Figure 9, $B$ and $E$, and the overlying cones with the terminal aggregates are shown in Figure 9, $C$ and $F$. Figure 10 quantifies the relationship between dendritic field size and the number of cones. Generally, the number of cones contained within the dendritic field of a B-type cell increases with dendritic field size. The significance of the observed scatter is addressed at the end of Results.

A-type horizontal cells. A-type horizontal cells have a large range of dendritic field sizes, mainly due to the variability in the number and size of terminal arborizations. A-type cells with the largest dendritic spread were located in superior retina, and dendritic field sizes generally appear smaller in central than in peripheral retina. To give an estimate of A-type horizontal cell diameters, only dendrites bearing terminal arborizations were measured, because dendrites without terminal arborizations may not be complete. Dendritic lengths ranged from $120 \mu \mathrm{m}$ to 350 $\mu \mathrm{m}$, leading to estimated dendritic tree diameters of $240-700$ $\mu \mathrm{m}$. The effective dendritic field area of A-type cells like those displayed in Figure 7 was between 19,000 and 49,000 $\mu \mathrm{m}^{2}$. It is obvious that the bushy terminal arborizations contribute a large area to the dendritic field.

\section{Staining of horizontal cell populations}

Neurofilament immunostaining. EM examination revealed numerous NF bundles in A-type horizontal cell dendrites of the tree shrew retina (Fig. 11). Elongated "gap junctions" (presumably electrical synapses) are also found between the A-type dendrites (arrows in Fig. 11). NF immunostaining labels the whole population of A-type horizontal cells in the tree shrew retina, as confirmed by comparison with Nissl-stained material (see below). Hence, A-type cell densities can be readily determined. The labeled neurofilaments are located in the cell bodies and dendrites of A-type horizontal cells, which form a dense plexus in the OPL near the INL (Fig. 12). Vertical sections revealed additional strong immunoreactivity in ganglion cell axons and in fine processes in the inner plexiform layer (presumably amacrine or ganglion cell processes; Fig. 12A). There was no evidence of descending processes on A-type horizontal cells. The prominent NF-IR plexus in the OPL is best seen in horizontal $40 \mu \mathrm{m}$ sections (Fig. 12B-D). At low magnification A-type horizontal cell bodies are rather inconspicuous in the dense plexus (arrows in Fig. 12B). Processes from neigboring cells show extensive overlap. The density of the NF-IR plexus appears rather similar in regions of low (Fig. 12C) and high (Fig. 12D) A-type cell density.

Nissl staining of horizontal semithin sections. B-type horizontal cell densities were evaluated from a series of horizontal $5 \mu \mathrm{m}$ glycol methacrylate sections, stained with toluidine blue, because no specific marker for B-type horizontal cells was available. The outermost row of the INL consists mainly of horizontal cell somata. In the sections, the horizontal cell nuclei can be discriminated from those of bipolar or microglial cells (Fig. $13 A$ ). They are larger in size, and contain a more translucent, smoother karyoplasm and up to three large nucleoli. The nuclei of B-type cells are more spherical than those of A-type cells. Frequently, the perikarya of A-typc cells are faintly stained by toluidine blue. They appear polygonal because the thick stalks of the primary dendrites are also stained (Fig. 13A).

Neurobiotin labeling. Neurobiotin is a tracer molecule with a molecular weight smaller than that of LY. When applied intracellularly in living isolated retina, Neurobiotin crosses gap junctions that are too small for LY passage (Vaney, 1991). We injected Neurobiotin into A- and B-type horizontal cells of the tree shrew retina and often found that around the injected cell a patch of homologous cells also contained the tracer, presumably via gap junctional coupling (Fig. 13B). In some instances the tracer did not travel beyond the injected cell, possibly because of adverse tissue conditions. Labeled patches contained up to 500 cells that were all of the same type as the injected cell, and the intensity of the label decreased evenly toward the periphery of the patch (Fig. 13B). Especially in the B-type patch- 

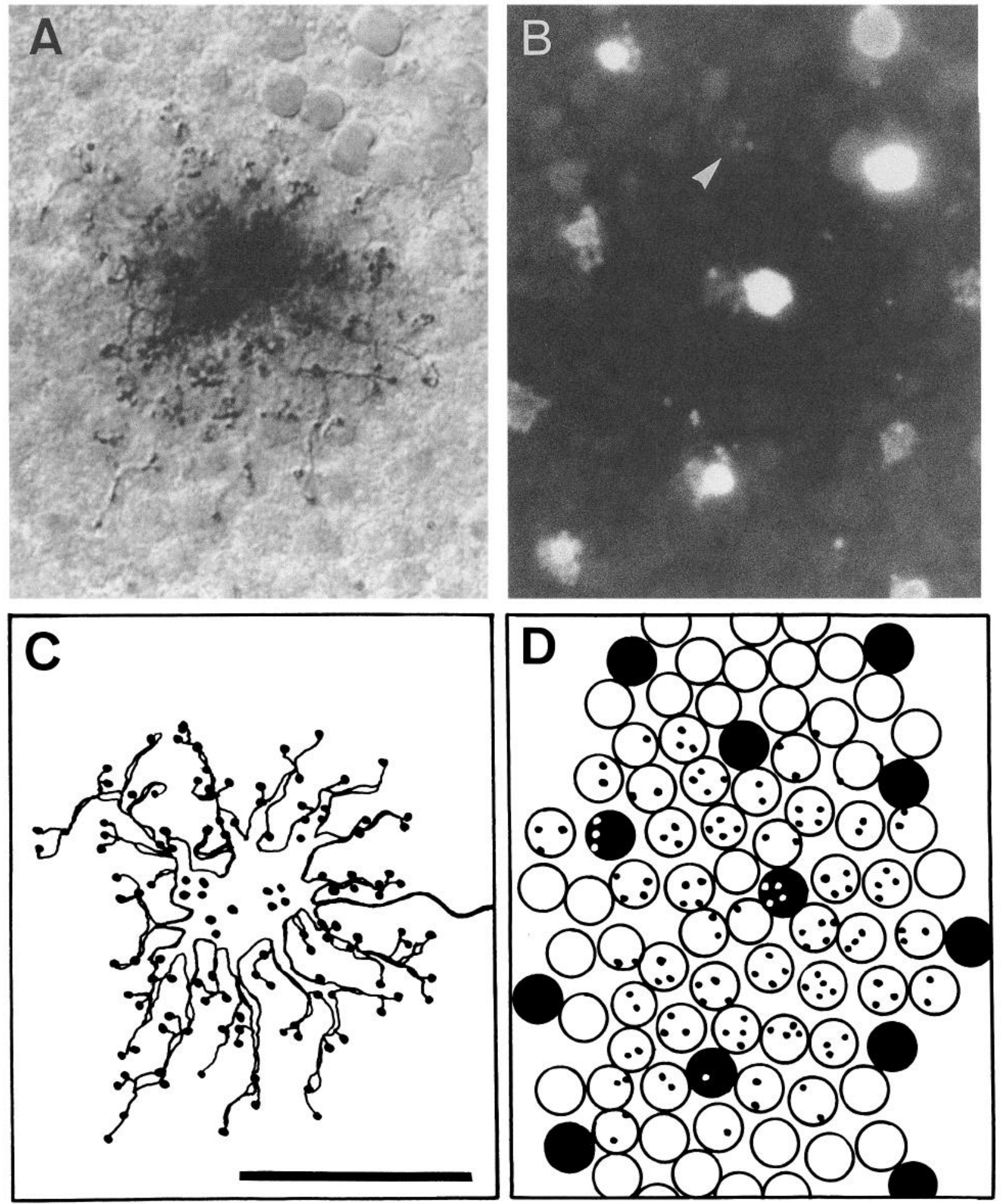

Figure 6. Visualization of B-type horizontal cell contacts with blue cones. A, Micrograph of an LY-injected and immunostained B-type cell under Nomarski optics. The focus is on the terminal aggregates in the OPL, and the pattern of cone pedicles is also visible (compare Fig. 2). $B$, Fluorescence micrograph of the same field as in $A$ after labeling the blue cones with an S-antigen antibody and an FITC-coupled second antibody. The focus is on the blue cone pedicles in the OPL. For better LY injection most cone nuclei have been brushed off (see Materials and Methods); two remaining blue cone nuclei are visible slightly out of focus at the top right. Cone pedicle preservation is also varying; the least complete blue cone pedicle is marked (arrowhead). $C$, Line drawing of the cell in $A$ including the terminals. $D$, Superposition of the cone pattern and the horizontal cell terminals. Blue cones (from $B$ ) are drawn as solid circles; the remaining red cones (from $A$ ), as open circles. Both types of cone are contacted by terminals. The circles idealize the irregular pedicle shape. Scale bar, $25 \mu \mathrm{m}$ for $A-D$. 


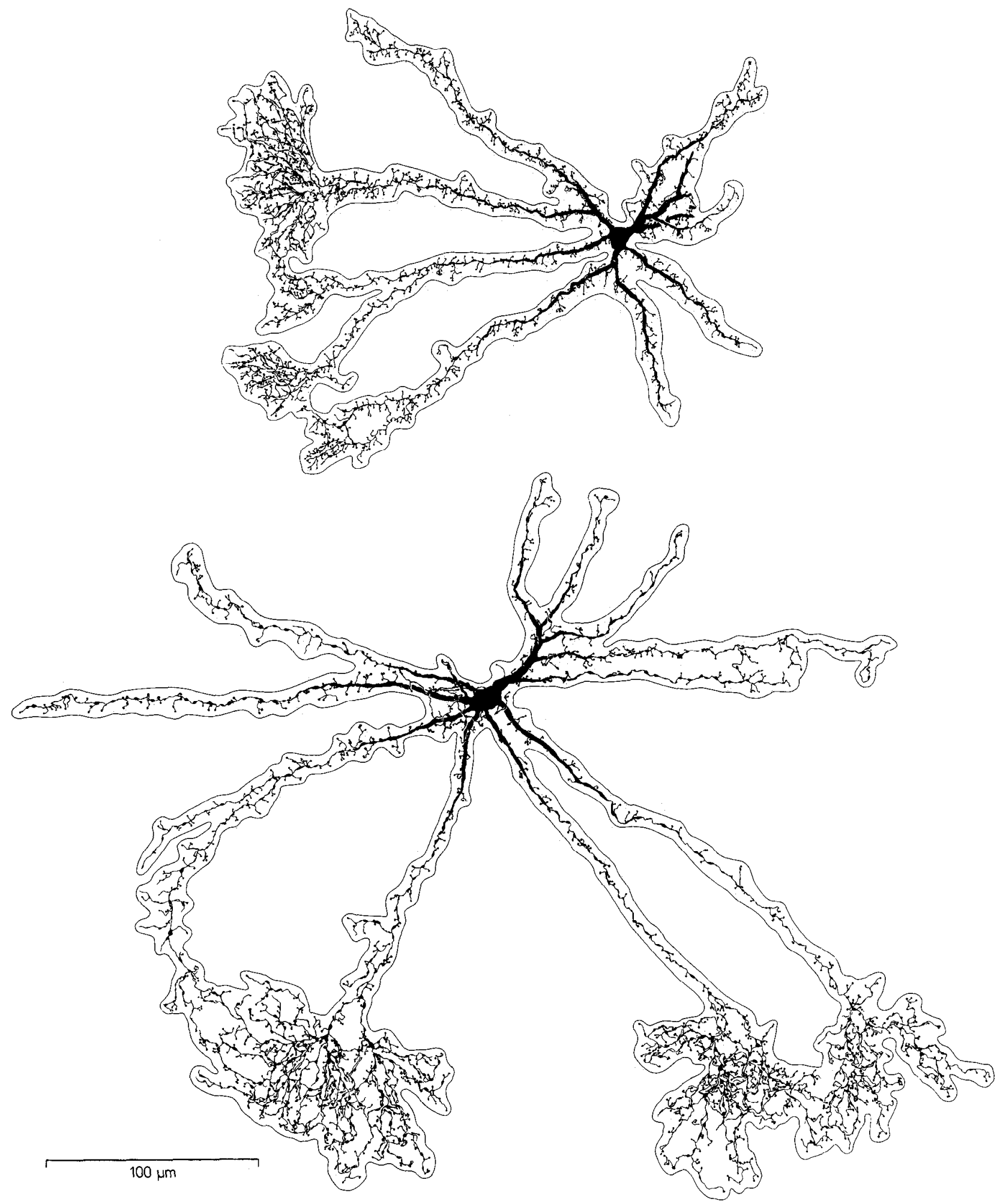

Figure 7. Line drawings of LY-injected A-type cells. Both cells are from superior temporal midperiphery, the larger cell being somewhat more peripheral. A line has been drawn around the dendrites at a distance of one cone pedicle diameter from the synaptic tcrminals. This defines the effective dendritic field area, that is, the region where the cell can potentially make cone contacts (see text). Large regions within the circumference of the cell are not reached by processes. Cones in those regions are contacted by the overlapping processes of neighboring cells (compare Fig. 12). 

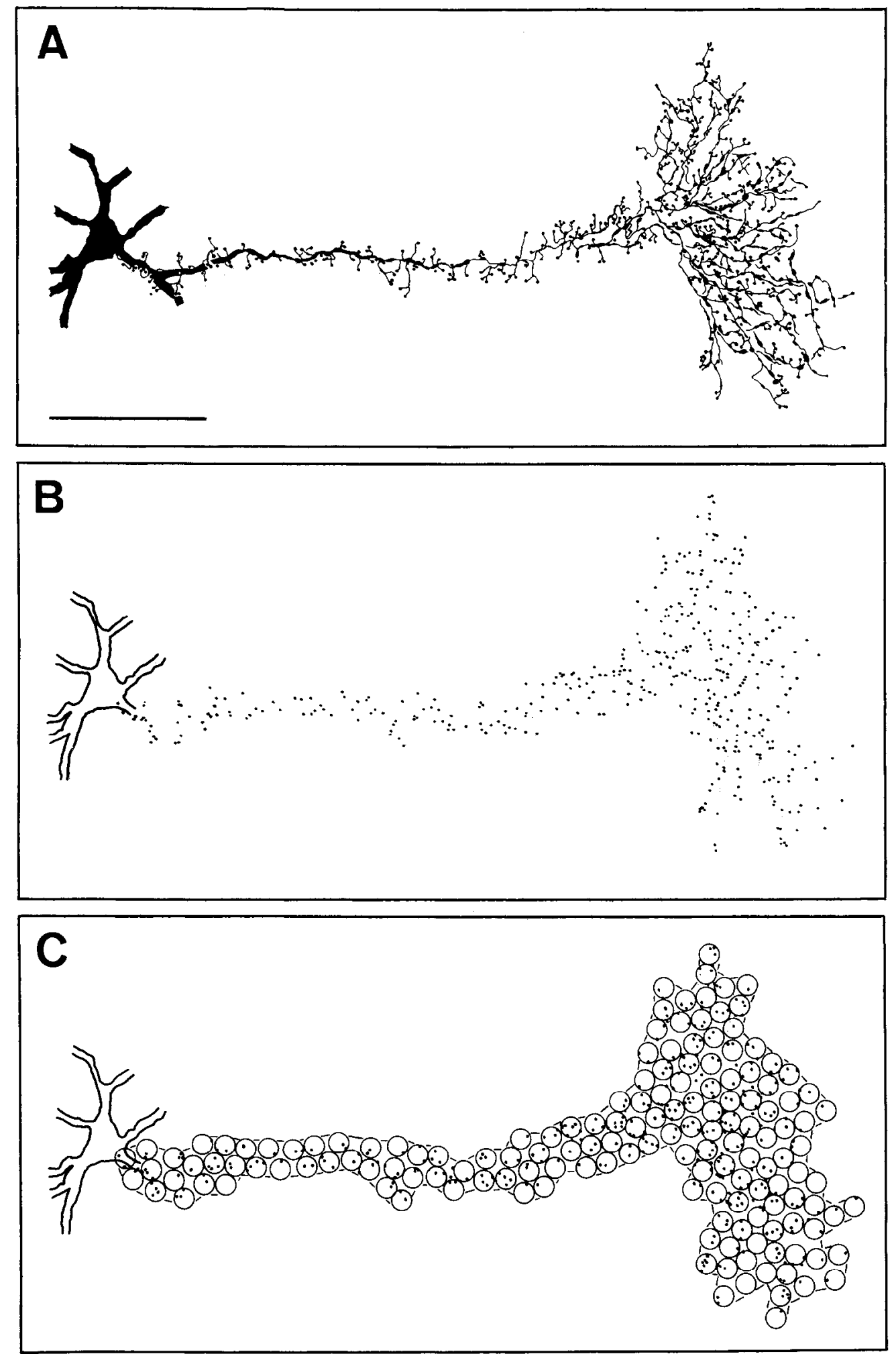

Figure 8. Cone contacts of an A-type horizontal cell. $A$, Line drawing of an A-type dendrite with a bushy terminal arborization. $B$, Isolated pattern of its terminals (cone contacts). $C$, Terminals and the overlying cone pattern. The effective dendritic field area of this dendrite is indicated by a broken thin outline. Along the main dendrite and the region of the bushy terminal arborization nearly all cones are contacted by terminals. The circles idealize the irregular pedicle shape; thus, a perfect fit of all terminals with the circles is not to be expected. EM showed that no terminals contacted rod spherules. Scale bar, $50 \mu \mathrm{m}$. es, the cells were arranged in a rather regular pattern, suggesting that all members of the population were stained. The results indicate that gap junctions exist only between members of the homologous horizontal cell type and that all members are coupled. The Neurobiotin injections allowed an independent assessment of A- and B-type densities at selected locations. They corroborate the density values obtained with the other population stains.

\section{Mosaics of $A$ - and B-type cells}

Figure $14 \mathrm{~A}$ is a line drawing of a field of A- and B-type cells from Nissl-stained sections like that of Figure $13 A$. The spacing of B-type somata is rather even and close pairs rarely occur. A-type somata, on the other hand, are less regularly spaced and close neighbors are found more often. The same differences in soma arrangement were also observed in Neurobiotin-injected 

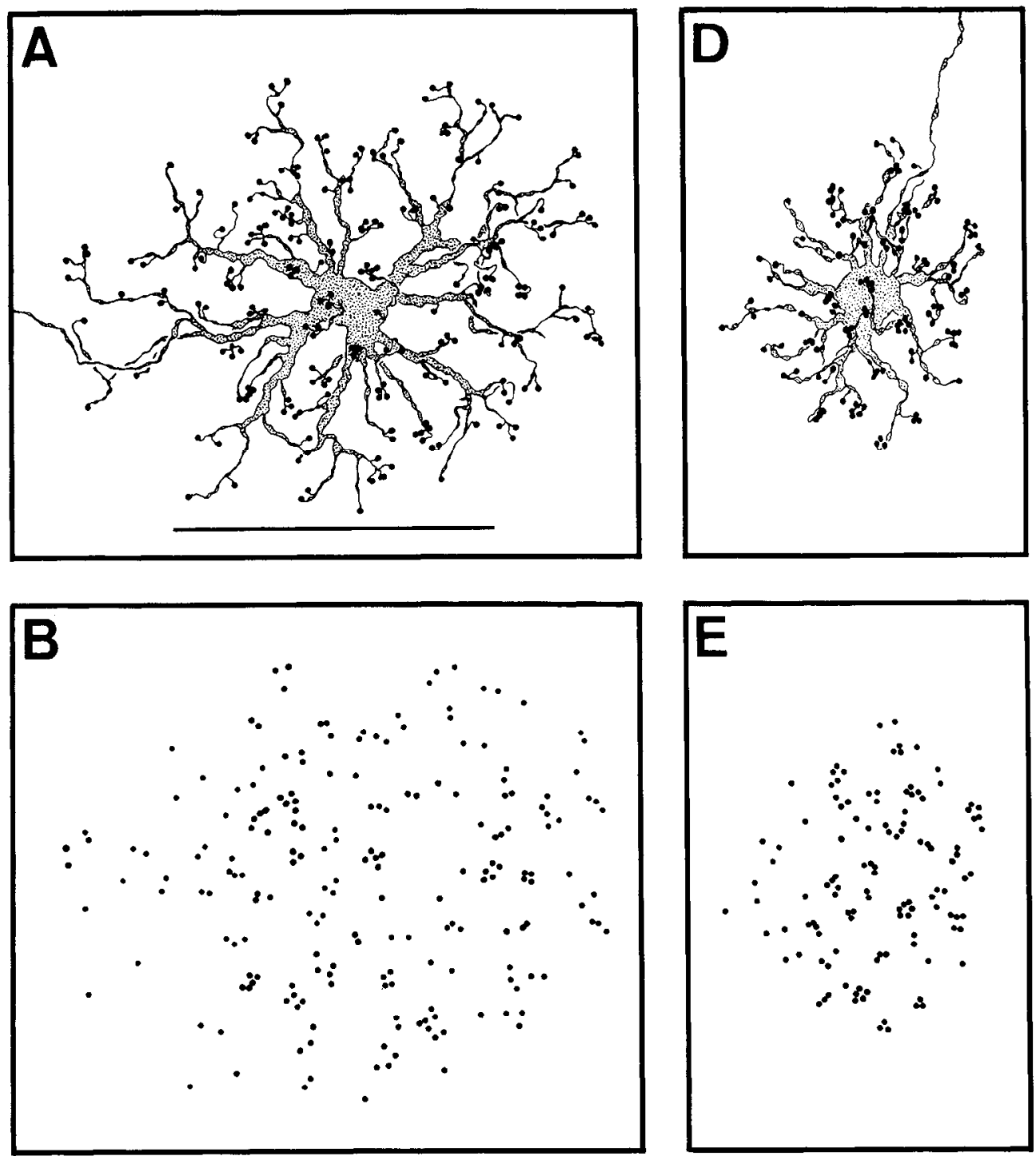

Figure 9. Cone contacts of B-type horizontal cells: line drawings of B-type cells from a low-density region in superior periphery $(A)$ and a high-density region in inferior midperiphery $(D)$. The isolated pattern of terminals is given in $B$ and $E$ and the overlying cone pattern is added in $C$ and $F$. The larger cell $(A)$ has 93 cones in its dendritic field of $4450 \mu \mathrm{m}^{2}$ (circumference outlined in $C$ ). The smaller cell $(D)$ has 46 cones in its dendritic field of $1700 \mu \mathrm{m}^{2}$. Here the cones have smaller diameters than at the location of the larger cell ( $5 \mu \mathrm{m}$ vs. $7 \mu \mathrm{m})$, and the terminal aggregates are correspondingly closer packed. Only very few cones do not receive terminals. For the slight mismatch of some terminals see Figure 8 caption. Scale bar in $A$ is $50 \mu \mathrm{m}$ for $A-F$.
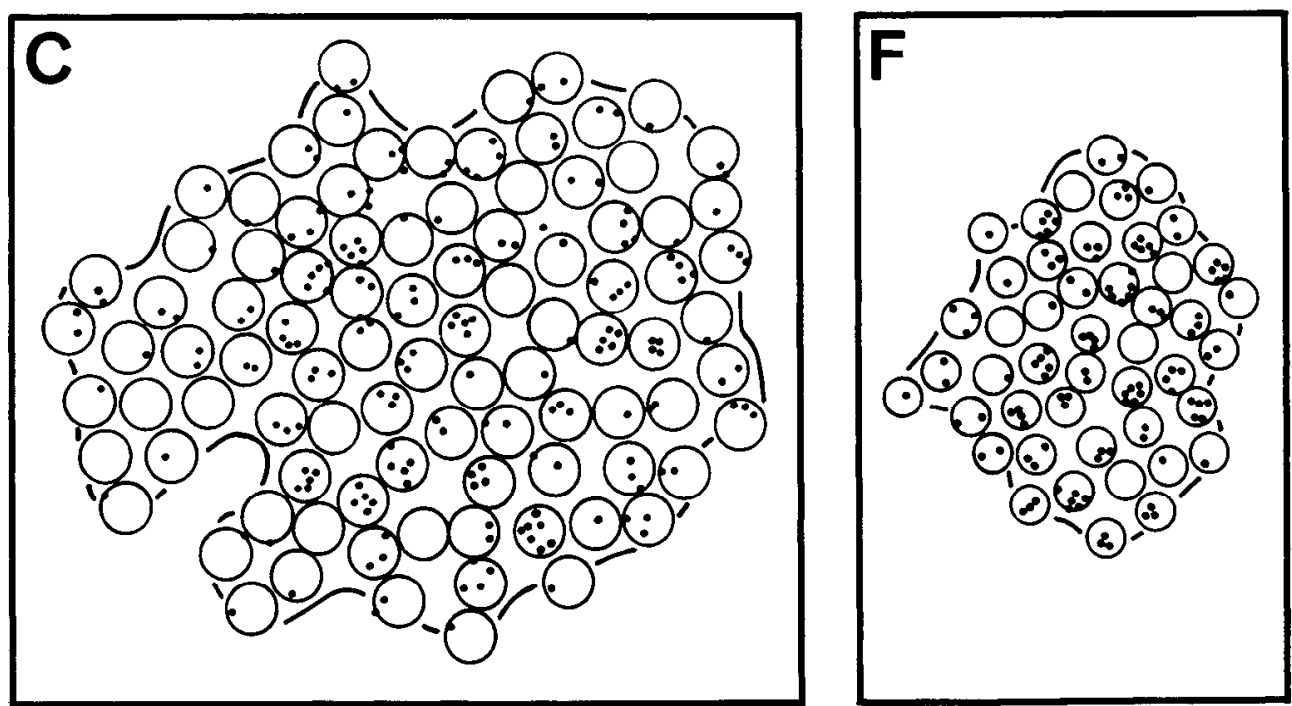

patches, where B-type patches always showed a more regular mosaic than A-type patches (compare Fig. 13B).

To quantify the regularity of the horizontal cell arrangements, a nearest neighbor analysis (Wässle and Riemann, 1978) was performed on the separate mosaics of the A-type and B-type populations (Fig. 14B, top and middle) and on the entire horizontal cell population (Fig. 14B, bottom). Using the formulas given in Wässle and Riemann (1978) we established that for all 


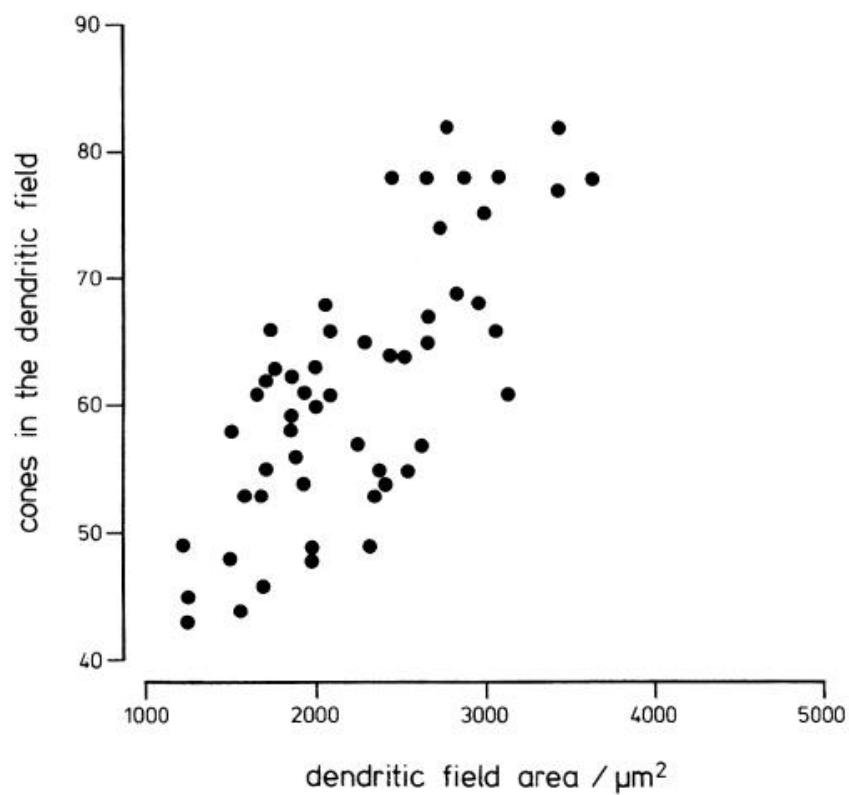

Figure 10. Correlation between dendritic field area and number of cones in the dendritic field for B-type horizontal cells. For details, see Results.

three populations the histograms of nearest neighbor distances are better fitted by a Gaussian curve than by a Poisson curve that would describe the distances in a random pattern of the same density. This shows that the cell spacing is statistically regular. The precision of the mosaics can be expressed by the ratio $r$ of the mean over SD of the distributions; the greater this value, the more regular the array. The regularity index of B-type cells is $r=6.3$, confirming that their arrangement is more regular than that of A-type cells $(r=3.9)$ and of the mixed population $(r=3.9)$. The low regularity of the A-type spacing is taken up in Discussion.

\section{Topographical distribution of A-type and B-type cells}

The density distribution of NF-IR A-type horizontal cells is given in Figure 15A. The grade of shading indicates the density, which varies with retinal location between 450 and 1220 cells/ $\mathrm{mm}^{2}$, by a factor of 2.7 . Densities higher than $1150 \mathrm{cells} / \mathrm{mm}^{2}$ are found in patches in an elongated strip extending nasotemporally in central retina. A large area with relatively high densities $\left(>1000\right.$ cells $\left./ \mathrm{mm}^{2}\right)$ extends into the inferior hemiretina. The central area (where ganglion cell density is highest) is located at the temporal edge of the high density region. In large parts of the superior retina, A-type densities are lower than 800 cells/ $\mathrm{mm}^{2}$. Overall, A-type densities decrease from central to peripheral retina, but density changes are less smooth than those of the B-type cells (Fig. 15B). A-type densities assessed in the Nissl-stained sections (compare Fig. 13A) are in good agreement with the data of neurofilament-stained material.

The density distribution of B-type horizontal cells is given in Figure $15 B$. It is derived from counts of the entire horizontal cell population in Nissl-stained semithin sections by subtracting the A-type densities. The grade of shading indicates the density, which varies between 1050 and 3120 cells $/ \mathrm{mm}^{2}$, by a factor of

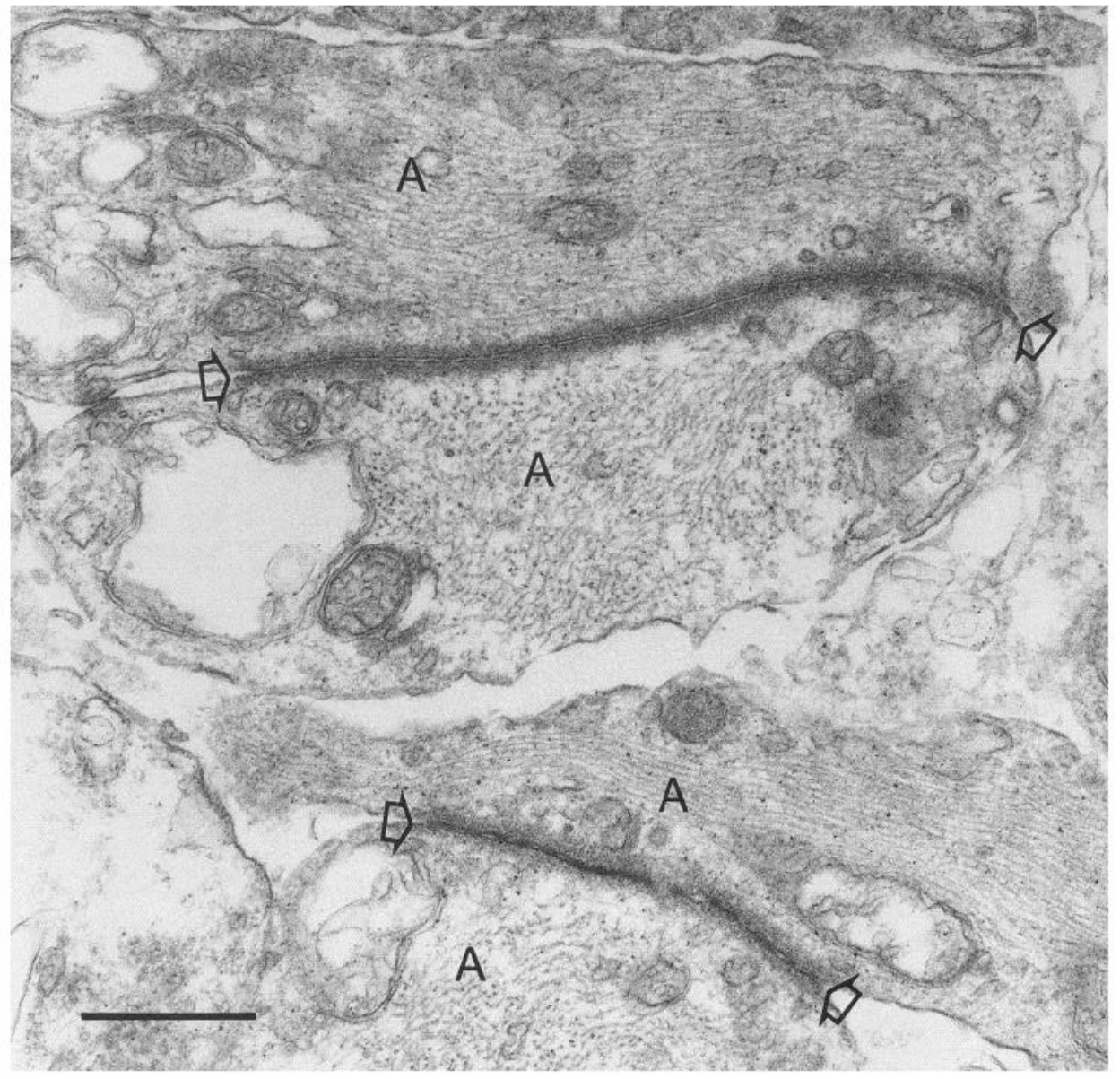

Figure 11. Electron micrograph of four main dendrites $(A)$ of A-type horizontal cells in the OPL. The cytoplasm contains many NFs that are arranged in parallel to the axis of the dendrite. $A r$ rows mark the large gap junctions between A-type dendrites. Scale bar, 0.5 $\mu \mathrm{m}$. 

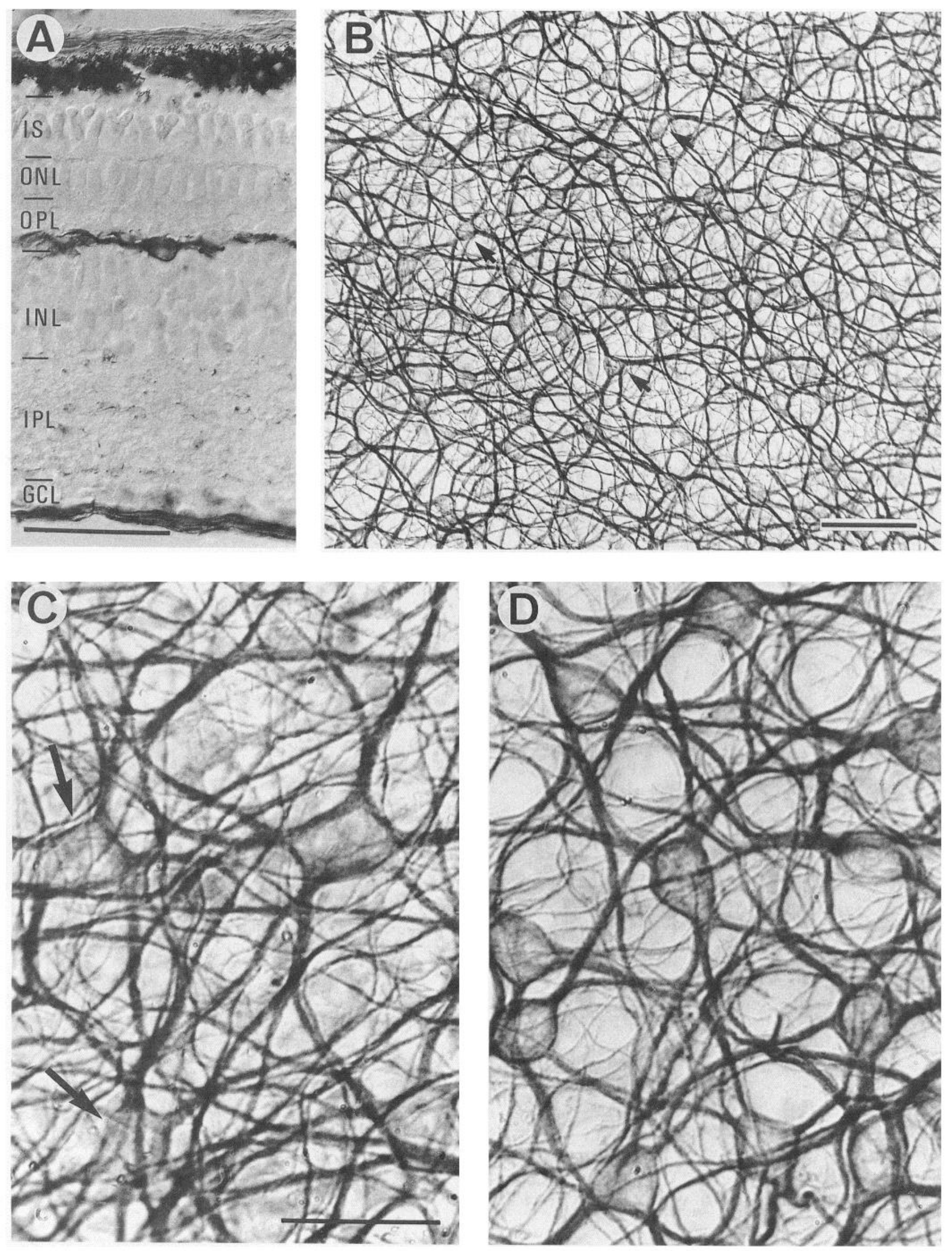

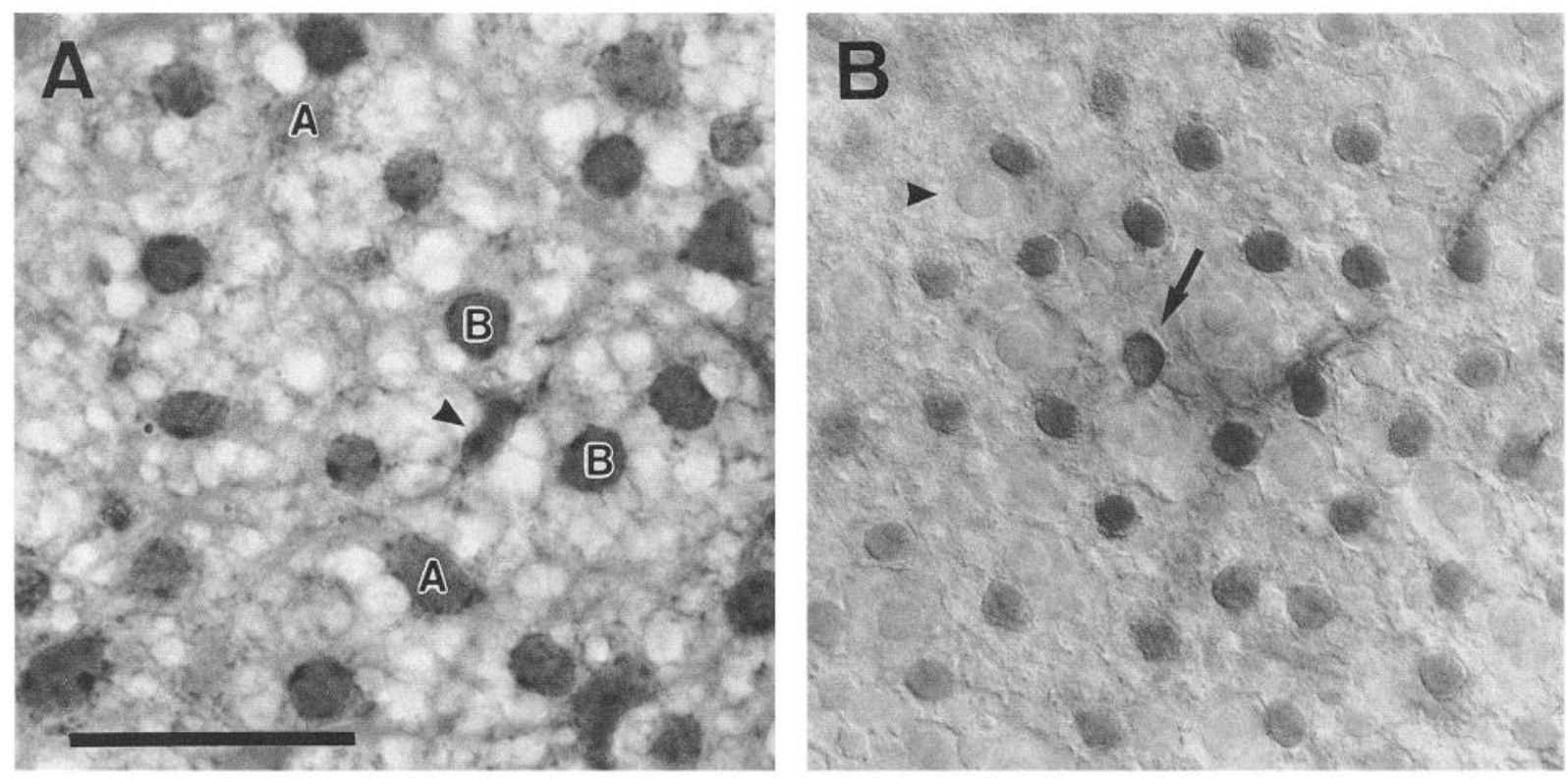

Figure 13. Population staining of horizontal cells. $A$, Micrograph from a toluidine blue-stained $5 \mu \mathrm{m}$ horizontal section through the outer part of the INL, at the level of the horizontal cell somata. The larger polygonal somata are those of A-type cells, the more numerous smaller round somata are those of B-type cells (some labeled with $A$ and $B$, respectively). Smaller soma-like structures are microglia or calottes of bipolar cell somata; other larger structures are capillary components (arrowhead). B. Micrograph of the horizontal cell layer in a whole-mount piece where a patch of B-type cells is labeled after injection of one B-type cell (arrow) with Neurobiotin. The intensity of the tracer decreases toward the periphery of the patch. The B-type somata are regularly arrayed. The somata of unlabeled A-type cells are also visible in this Nomarski micrograph (one labeled by an arrowhead). Scale bar: $25 \mu \mathrm{m}$ for $A, 50 \mu \mathrm{m}$ for $B$.

3. For selected locations, these data were confirmed by Neurobiotin injections. In general, B-type densities decrease smoothly from central to peripheral retina. The distribution has some similarities to the A-type cell distribution; higher densities are located in central and inferior retina, and lower densities are located in superior retina. Density maxima of B-type cells, however, are located more inferiorly in the retina than those of A-type cells. The density distribution of the entire horizontal cell population mainly reflects the gradients of the B-type cells because they are more numerous than the A-type cells. Total densities vary between 1500 and 4400 horizontal cells $/ \mathrm{mm}^{2}$. The ratio of B-type to A-type cells is between 1.6 and 2.9, depending on retinal location.

As B-type cell density decreases, dendritic field size conversely increases from central to peripheral retina by a factor of 3.6 (compare Fig. 9). Dendritic field areas are larger than $4000 \mu \mathrm{m}^{2}$ at low densities (1050-1400 cells $\left./ \mathrm{mm}^{2}\right)$ and smaller than 1700 $\mu \mathrm{m}^{2}$ at high densities $\left(2700-3120\right.$ cells $\left./ \mathrm{mm}^{2}\right)$. The resultant coverage factor (the product of dendritic field area and density; Wässle et al., 1978b) is 4-6 and rather independent of retinal location. Since B-type horizontal cells innervate all cones in their dendritic field, it follows that each cone receives terminals from 4-6 B-type horizontal cells. We did not calculate the coverage factor of A-type horizontal cells because the completeness of their staining is in doubt (see Discussion).
The photoreceptor distribution of the particular retina illustrated in Figure $15 B$ has previously been evaluated and published (Fig. 5A,D in Müller and Peichl, 1989). Hence, cone densities and horizontal cell densities of the same retina are available to obtain cone-to-horizontal cell density ratios directly. The ratio of cones to A-type horizontal cells ranges between 20 and 30 over large parts of the retina. The ratio of cones to B-type horizontal cells ranges between 9 and 12 . The difference between the cone density gradient and the density and dendritic field size gradients of B-type horizontal cells means that a given B-type dendritic field size can be found at various cone densities. This explains the scatter seen in Figure 10.

\section{Discussion}

The present study confirms and further analyzes the two distinct types of horizontal cell in the tree shrew retina first described by Mariani (1985). It focuses on the photoreceptor contacts of these cells and their size and density changes across the retina. In the following, these data are used to compare tree shrew horizontal cells with those of other mammals. The tree shrew retina is exceptional in its cone dominance and offers a unique opportunity to study the phylogenetic flexibility of retinal neuron types whose properties are at present mainly known from rod-dominated species.

\footnotetext{
Figure 12. A-type horizontal cells labeled with an antibody against neurofilaments. $A, \mathrm{NF}$ immunoreactivity seen on a vertical section. A-type horizontal cells at the border of the $I N L$ and $O P L$ are labeled; in addition there are labeled ganglion cell axons $(G C L)$ and a sparse labeling of processes in the inner plexiform layer $(I P L)$. IS, photoreceptor inner segments; $O N L$, outer nuclear layer. $B-D$, NF-IR A-type cells in horizontal sections of the outer retina. B, Low-power view of a region in temporal retina with an A-type cell density of $900 / \mathrm{mm}^{2}$. The somata (three marked by arrows) are difficult to detect in the dense plexus of overlapping dendrites. At higher power, the somata are more obvious: $C$, region in superior retina with a low cell density of $660 / \mathrm{mm}^{2}$ (two somata arrowed); $D$, region from nasal retina with a high cell density of $1100 / \mathrm{mm}^{2}$. Scale bars: $A$ and $B, 50 \mu \mathrm{m} ; C, 25 \mu \mathrm{m}$ for $C$ and $D$.
} 
A

Figure 14. Mosaic of horizontal cells in the tree shrew retina. $A$, Field from temporal retina at a density of 1220 A-type cells $/ \mathrm{mm}^{2}$ and 2820 B-type cells/ $\mathrm{mm}^{2}$, drawn from a toluidine bluestained $5 \mu \mathrm{m}$ horizontal section. The B-type somata (open circles) appear more regularly arrayed than the somata of A-type cells (solid profiles). B, Quantification of the mosaic by a nearest neighbor analysis. The histograms give nearest neighbor distances for the A-type and B-type populations and for the mixed population, measured in a field containing $A$ but being twice that size. For details, see text.
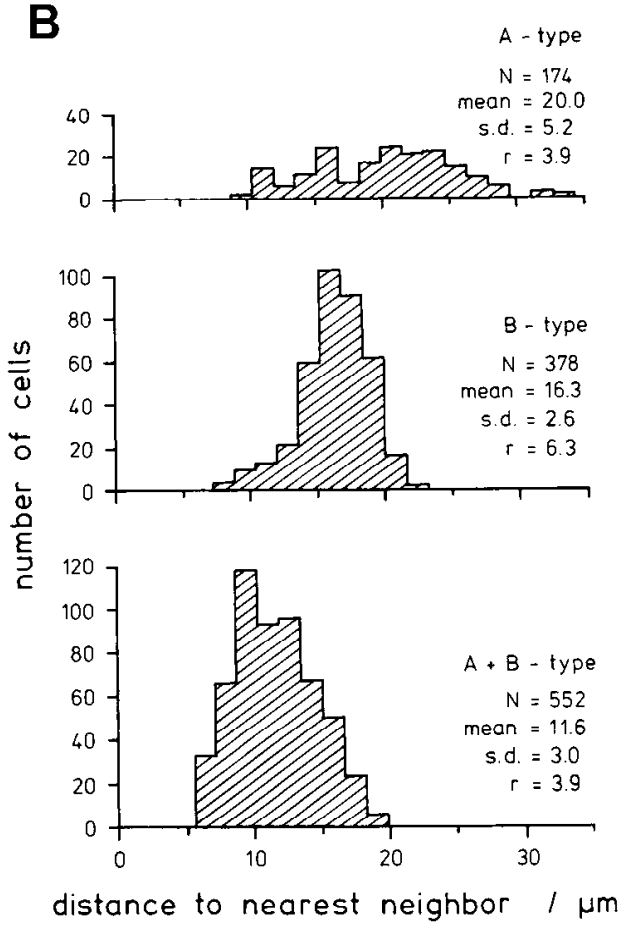

\section{Morphological types}

Mammalian retinas generally have two types of horizontal cell, termed A-type and B-type (HII and HI, respectively, in primates). In all mammals studied to date, the B/HI-type cell has an axon with an axon terminal system. B/HI-type cell dendritic trees make contacts exclusively with cones, whereas their axon terminal systems make contacts exclusively with rods (reviewed in Boycott et al., 1987). A-type cells are axonless in most species, and their dendritic trees contact cones exclusively. The primate retina is an exception, where the HII cell (corresponding to A-type) has an axon that, however, also contacts cones (Kolb et al., 1980). The ox retina is another case where both types have an axon (Ramon y Cajal, 1893; B. B. Boycott, personal communication).

Mariani (1985) has termed the smaller tree shrew horizontal cell "uniaxonal" and the larger type "multiaxonal," regarding the bushy terminal arborizations as multiple axon terminal systems unparalleled by any other vertebrate horizontal cell, and discussing that they may make both rod and cone contacts. For Mariani this apparent diversity of morphologies argues against a common basic pattern of horizontal cell types in mammals. In contrast, our extended data lead us to the conclusion that tree shrew horizontal cells conform to the two basic mammalian types, with some modifications attributable to the special photoreceptor arrangement.

All our LY-injected horizontal cells could be classified as A-type or B-type. The injection of about 400 horizontal cells was done without prelabeling of somata, that is, by chance and without selection; the sample thus appears unbiased. We regard this as strong evidence that the tree shrew retina has only two types of horizontal cell.

B-type horizontal cells. By morphology and photoreceptor contacts, tree shrew B-type cells are very similar to the $\mathrm{B} / \mathrm{HI}$ type cell found in the retinas of all mammals studied (reviewed in Boycott et al., 1987). This includes rodents, where we did not find A-type cells (Peichl and González-Soriano, 1993), and also marsupials (Harman and Beazley, 1991). It is not surprising that the tree shrew also has this phylogenetically conserved cell type.

The only marked difference to other mammals is that the axons of tree shrew B-type cells have very few ramifications and terminals; Mariani (1985) reports 5-10 terminals per axon. The $\mathrm{B} / \mathrm{HI}$-type axons in rod-dominated mammals have a profuse axon terminal system that exclusively contacts rods (cat, Kolb, 1974; monkey, Boycott and Kolb, 1974; rabbit, Dacheux and Raviola, 1982). For technical reasons we could not establish directly whether the axon terminals of tree shrew B-type cells also contact rods. This, however, is very likely because the axon terminals are as sparse as the rods, and because tree shrew rod spherules have triad synapses with lateral elements and are thus expected to make horizontal cell contacts (Dieterich, 1969; Müller and Peichl, 1991a). As all other terminals of A- and B-type cells are here shown to contact cones, only the B-type axon terminals remain for rod contacts. At all retinal locations, the B-type density is about as high or higher as the rod density (Müller and Peichl, 1989), so the few terminals per B-type axon would suffice to occupy the lateral positions in the rod triad synapses.

In three other diurnal mammals with cone-dominated retinas - the ground squirrel, the gray squirrel, and the red squirrel-axon-bearing horizontal cells with a B-type morphology have been described (West and Dowling, 1975; West, 1978; Mariani, 1985). In these species the axon also lacks an elaborate axon terminal system. However, EM examination of one such axon in ground squirrel retina revealed cone contacts (West and Dowling, 1975).

A-type horizontal cells. Tree shrew A-type cells share significant features with the A/HII-type horizontal cells of other mammals (reviewed in Boycott et al., 1987). Generally, the A-type cells are substantially larger than the B-type cells and 
have a more sturdy, sparsely branched dendritic tree, and their photoreceptor contacts are exclusively with cones. Tree shrew A-type cells, like those of several other mammals, contain large amounts of neurofilaments (Fisher and Boycott, 1974; Wässle et al., 1978b; Silveira et al., 1989; Vickers and Costa, 1992; Yamada et al., 1992).

The most peculiar feature of tree shrew A-type cells is the profuse terminal arborizations at many dendrites, which have no counterpart in the horizontal cells of other species. Because the dendrites thin down and in Golgi material show only a few terminals between the center of the dendritic field and the peripheral ramifications, Mariani (1985) regarded the cells as multiaxonal. Our data show that the whole length of the dendrites up to the ultimate ramifications is studded with terminals that contact all concs in reach (compare Fig. 8). This is not characteristic of axonal processes and represents a continuation, rather than a separation, of distinct morphological portions of the cell. Horizontal cell axons in other species carry few or no terminals. Thus, there is no reason to regard the thin processes of tree shrew A-type cells as axonal.

The terminal arborizations may contact as much as $50 \%$ of the cones contacted by the cell. The modified dendritic "gestalt" and the large dendritic field area increase the number of cones contacted per cell in this cone-dominated retina. It is puzzling, however, that branching is not increased evenly throughout the dendritic field to achieve this increase. This peculiarity apart, the cells are basically like A-type cells in other mammalian retinas. The cone contacts on the main dendrites and on the peripheral arborizations of A-type cells look very similar ultrastructurally; they give no indication of a functional polarity. In summary, we interpret trec shrew A-typc cells as modified mammalian A-type cells and not as a special type.

\section{Are B-type and A-type horizontal cells color specific?}

Tree shrews are diurnal dichromats of the deuteran type; that is, they have only blue-sensitive and red-sensitive cones (Jacobs and Neitz, 1986; Petri and Hárosi, 1990). By LY injection and subsequent $\mathrm{S}$-antigen immunohistochemistry, we could show directly that both types of horizontal cell contact red-sensitive and blue-sensitive cones. This was corroborated by showing for a larger number of cells that A- and B-type cells contact practically all cones (93-100\%) within their dendritic field. Thus, there is no structural evidence for cone selectivity and chromatic organization of tree shrew horizontal cells. A-type cells show no chromatic polarity between the central dendrites and the terminal arborizations since they contact red-and blue-sensitive cones in all parts of their dendritic tree.

Tree shrew horizontal cells thus conform to the cone connectivity found in other mammalian retinas. Individual cat, rabbit, and monkey horizontal cells contact between $80 \%$ and $100 \%$ of the cones in their dendritic field; as in tree shrew, the uncontacted cones do not form any obvious pattern that would indicate a specific cone type (Wässle et al., 1978a, 1989; Boycott et al., 1987; Raviola and Dacheux, 1990). Because of the overlap of neighboring cells, the population of each horizontal cell type contacts all cones and color selectivity of the horizontal cell types can be excluded in these species. A possible cone selectivity is claimed for human horizontal cells by some authors (Kolb et al., 1980, 1992; Kolb, 1991; Kolb and Ahnelt, 1992), and for the odd "C-type" horizontal cell of the rabbit (Famiglietti, 1990). It is controversial whether these observations indicate chro-
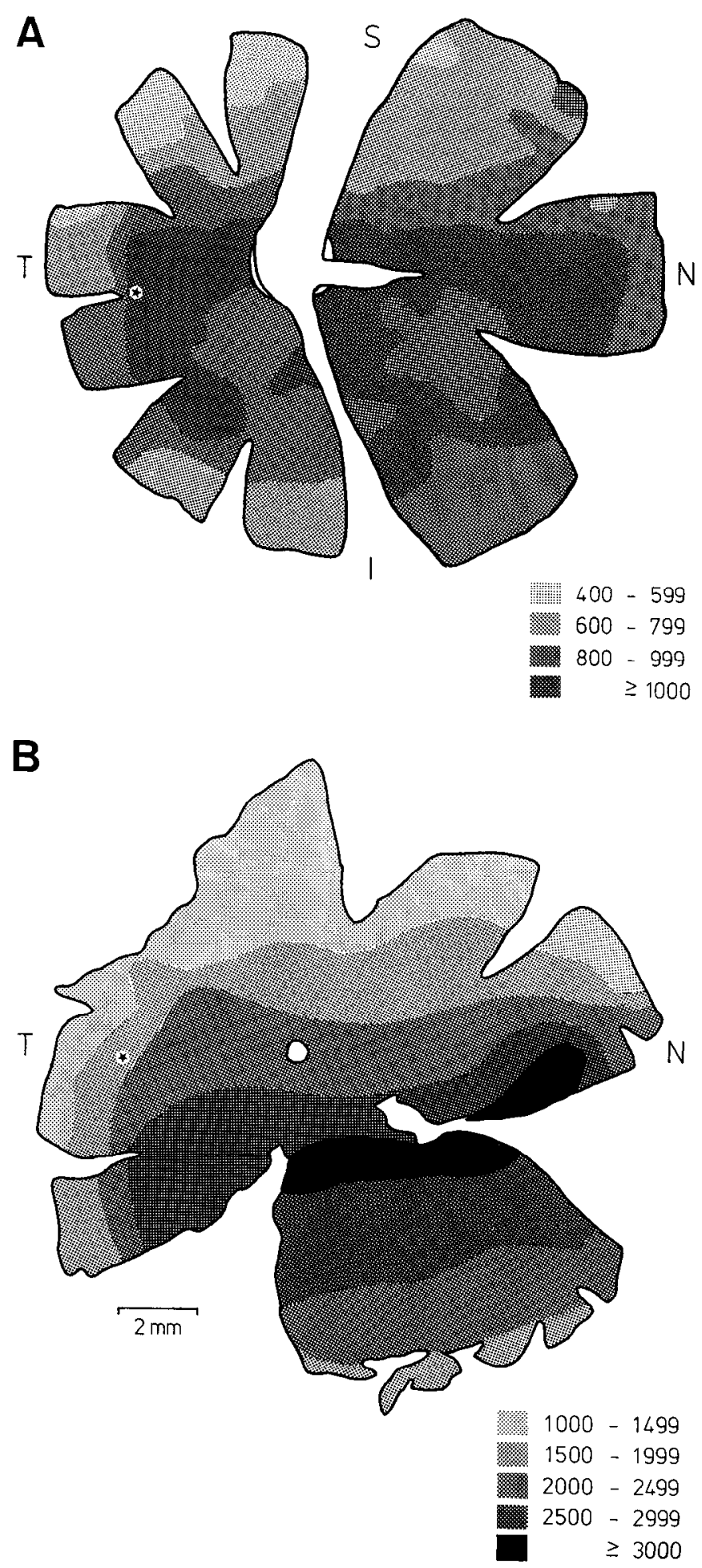

Figure 15. Maps of the density distributions of A- and B-type horizontal cells. $A$, Density distribution of A-type cells in a right retina, evaluated and reconstructed from NF-immunolabeled $40 \mu \mathrm{m}$ horizontal sections. $B$, Density distribution of B-type cells in a right retina, evaluated and reconstructed from toluidine blue-stained $5 \mu \mathrm{m}$ horizontal sections. The shading indicates the density and the legend gives densities in cells $/ \mathrm{mm}^{2}$, not corrected for shrinkage. Both maps are at the same scale. The small white areas in central retina indicate the optic disk; the asterisk marks the position of the central area. $N$, nasal; $T$, temporal; $S$, superior; $I$, inferior. 
matically organized horizontal cells (cf. Boycott et al., 1987; Boycott, 1988).

\section{Cell coupling via gap junctions}

EM examination revealed large gap junctions between tree shrew A-type horizontal cells (Fig. 11). Gap junctions are also found between the A-type cells of monkey, cat, and rabbit retina (Raviola and Gilula, 1975; Kolb, 1977), and dye coupling for LY is found between rabbit A-type horizontal cells (Dacheux and Raviola, 1982). Recent injection experiments with the smaller molecule Neurobiotin indicate gap junctions also between B-type horizontal cells of cat and rabbit retina (Vaney, 1991). Our Neurobiotin injections into tree shrew horizontal cells revealed patches of up to about 500 labeled cells of the same type around the injected cells. This argues for homologous coupling of Aand B-type horizontal cells also in the tree shrew. Density counts show that within the A- or B-type patches, all members of the population are labeled, indicating that gap junctions exist between all neighbors of the same type. Although the role of horizontal cell coupling in retinal information processing is not yet understood in detail, it can be stated that tree shrew horizontal cells have basically the same structural prerequisites as those of other species.

\section{Horizontal cell density distributions}

In the tree shrew retina maximal densities of A-type horizontal cells are located in a band extending horizontally approximately at the level of the optic nerve head, with high densities also extending into inferior retina. B-type cells have their density maximum in a roughly horizontal band in inferior retina. This is unusual in two respects. First, in cat and monkey, where horizontal cell topographies have been examined, the density maxima of both types colocalize (Wässle et al., 1978b, 1989). Without further information about the genesis of horizontal cell topographies, colocalized maxima appear reasonable. Differing topographic distributions are thought to originate, at least in part, from different birth dates of the neurons and hence different exposure times to nonuniform retinal growth (for a recent review, see Robinson, 1991). Our results may thus indicate different ontogenetic patterns for tree shrew A- and B-type cells. It is unclear what functional consequences disparate density maxima of the A- and B-type cells may have.

Second, mammalian horizontal cell density maxima usually coincide with those of the cones and the ganglion cells. This holds for the central area of the cat (Wässle et al., 1978b) and for the visual streak of the rabbit (Honrubia and Elliot, 1969; Reichenbach and Wohlrab, 1983; A. Reichenbach, personal communication). In monkey the horizontal cell peak is approximately colocalized with the ganglion cell peak in an annulus around the fovea, where the foveal cone pedicles end (Wässle et al., 1989). In capybara the A-type density maximum is colocalized with that of the ganglion cells in the visual streak (Yamada et al., 1992; the photoreceptor topography is not known in this species). In tree shrew neither horizontal cell type has peak densities at the location of peak ganglion cell densities in the central area. The density maximum of the B-type cells, but not of the A-type cells, roughly coincides with that of the cones, which also have their highest densities in inferior midperipheral retina (Müller and Peichl, 1989). The odd mismatch between the cone and ganglion cell topographies has been addressed previously (Müller and Peichl, 1989).

\section{Dendritic field sizes and coverage}

The dendritic field sizes of B-type horizontal cells in the tree shrew retina increase from central to peripheral retina by a factor of 3.6. The number of cones contacted by individual B-type cells increases roughly in parallel with dendritic field size (Fig. 10). In monkey HI and HII cells, the number of contacted cones also increases from central to peripheral retina (Boycott et al., 1987; Wässle et al., 1989), whereas in cat A- and B-type cells it decreases (Wässle et al., 1978a). This reflects species differences in the relation between the cone density changes and the size changes of the horizontal cells across the retina. The coverage of the tree shrew retina with B-type horizontal cells changes relatively little with eccentricity; at each location the dendrites of 4-6 B-type cells overlap. Similarly, coverage factors of cat A- and B-type cells and of monkey HI and HII cells are 3-5 over most of the retina (Wässle et al., 1978b, 1989; Boycott et al., 1987). With an overlap of 4-6 B-type cells and an average number of 2.9 terminals per B-type terminal aggregate, each tree shrew cone pedicle receives about 12-18 B-type terminals.

Calculations of dendritic field areas and coverage factors for tree shrew A-type cells have to assume the cells are completely stained; this problem is addressed in Results. With this reservation, our largest A-type cells have estimated effective dendritic field areas of $19,000-49,000 \mu \mathrm{m}^{2}$. The size difference between A- and B-type horizontal cells is much larger in tree shrew than in other investigated mammals. In fact, the dendritic tree diameters of tree shrew A-type cells (240-700 $\mu \mathrm{m})$ are the largest reported in any mammalian retina, as is the number of contacted cones. With the above A-type dendritic field estimates and the corrcsponding A-typc densitics, the resulting coverage factor would be as high as $20-$ in contrast to cat and monkey, where A- and B-type coverage factors are similar (see above). As tree shrew A-type cells have a mean of 2.5 terminals per terminal aggregate, a coverage factor of 20 would provide about 50 lateral elements for each cone pedicle. Together with 12-18 B-type terminals, this would add up to about 60-70 lateral elements, or 30-35 triad synapses per cone pedicle. We evaluated one cone pedicle at the EM level and counted only 18 triads. If this number is representative, an A-type coverage factor of 20 has to be an overestimate; in other words, the average dendritic field areas of A-type cells have to be substantially smaller than the maxima given above. This is the case in our material and supports the view that most cells in fact are not understained. Even so, the A-type coverage is certainly larger than that of the B-type cells as evidenced by the densely overlapping NF-IR plexus (Fig. 12).

\section{The mosaic of horizontal cells}

The density distribution of A-type cells across the tree shrew retina is less smooth than that of the B-type cells (Fig. 15). On a finer scale the mosaic of the A-type somata is also less regular (regularity index $r=3.9$ ) than that of the B-type cells $(r=6.3)$, as revealed by a nearest neighbor analysis of the two populations. In fact, the regularity index of the A-type mosaic is not better than that of the mixed A- and B-type population. This is different from the arrangement of horizontal cells in the cat retina, where A- and B-type cells have similar grades of regularity (B-type, $r=6.0$; A-type, $r=6.7$; Wässle et al., 1978b), which are close to that of the tree shrew B-type mosaic.

Analysis of several retinal neuron types has led to the conclusion that homogeneous populations form regular mosaics 
(Wässle and Riemann, 1978; Wässle et al., 1981). The mosaic of tree shrew A-type cells is less regular than that of cat horizontal cells, but more regular than A-type horizontal cells in ventral capybara retina $(r=3.5$; Yamada et al., 1992) and displaced cholinergic amacrine cells in rabbit retina $(r=3.3$; Vaney et al., 1981), and about as regular as, for example, rabbit and ferret inner $\alpha$-ganglion cells ( $r=4.0$ and 3.8, respectively; Peichl et al., 1987a,b). All these distributions are distinct from random distributions and represent single cell types. Our LY injections gave no indication of a heterogeneity in A-type morphologies, and the relatively low regularity index is no reason to doubt the homogeneity of the tree shrew A-type population.

It has been hypothesized that the regular mosaic of homogeneous neuron populations reflects a "territorial" mechanism; soma spacing and dendritic field dimensions are correlated so that a homogeneous and economical coverage of the retina is achieved (Wässlc and Ricmann, 1978; Wässlc ct al., 1981). According to this hypothesis, during development dendritic trees grow until they get into "competitive interactions" with the dendritic trees of neighboring cells. For a regular array of cells, the dendritic trees should be approximately circular. This holds true for the densely branched tree shrew B-type cells as well as for the horizontal cells of cat and monkey (Wässle et al., 1978b, 1989). For tree shrew A-type cells the situation is different. They have loosely branched dendritic trees and an effective dendritic field of irregular outline (see Results and Fig. 7 for the definition of the effective dendritic field). In order to achieve a homogeneous coverage and reach all cones, the dendrites of neighboring A-type cells have to interlace strongly to fill the large gaps in the individual trees; they cannot be territorial in the above sense. The rather homogeneous plexus seen in Figure 12 is evidence for such an interlacing. With the branching pattern of the A-type dendritic trees the soma spacing may be less critical for the achievement of a homogeneous coverage.

\section{Do tree shrew horizontal cells project directly to the brain?}

Recently, Conley and Friederich-Ecsy (1993) have describcd retinal ganglion cells of the tree shrew that are retrogradely labeled by horseradish peroxidase injections into the ventral lateral geniculate complex of the thalamus. Surprisingly, in addition to ganglion cell somata, there are a small number of more completely labeled cells with the morphology of the A- and B-type horizontal cells described here and by Mariani (1985). The authors conclude that these cells are ganglion cells, not horizontal cells. To the contrary, our results definitively show that the cells described here and by Mariani (1985) are true horizontal cells located in the outer retina and form characteristic mammalian photoreceptor contacts. Particularly the A-type cells do not have an axon and thus cannot project to the brain. Although Conley and Friederich-Ecsy's cells have a clear horizontal cell morphology, if they possess a centrally projecting axon they are a minority and may be an expression of developmental errors. The deviation is intriguing and deserves further attention, but while their retinal and central connectivity and their overall numbers are not known it is premature to speculate about their significance. On present evidence they appear to be a minority of obscure functional importance.

\section{References}

Boycott BB (1988) Horizontal cells of mammalian retinae. Neurosci Res [Suppl] 8:97-111.
Boycott BB, Kolb H (1974) The horizontal cells of the rhesus monkey retina. J Comp Neurol 148:1 15-140.

Boycott BB, Hopkins JM, Sperling HG (1987) Cone connections of the horizontal cells of the rhesus monkey's retina. Proc R Soc Lond [Biol] 229:345-379.

Conley M, Friederich-Ecsy B (1993) Functional organization of the ventral lateral geniculate complex of the tree shrew (Tupaia belangeri): I. Nuclear subdivisions and retinal projections. J Comp Neurol 328: $1-20$.

Dacheux RF, Raviola E (1982) Horizontal cells in the retina of the rabbit. J Neurosci 1:1486-1493.

Dieterich CF (1969) Die Feinstruktur der Photorezeptoren des Spitzhörnchens (Tupaia glis). Anat Anz 125:305-312.

Famiglietti EV (1990) A new type of wide-field horizontal cell, presumably linked to blue cones, in rabbit retina. Brain Res 535:174 179.

Fisher SK, Boycott BB (1974) Synaptic connexions made by horizontal cells within the outer plexiform layer of the retina of the cat and the rabbit. Proc R Soc Lond [Biol] 186:317-331.

Gallego A (1986) Comparative studies on horizontal cells and a note on microglial cells. Prog Retinal Res 5:165-206.

Harman AM, Beazley LD (1991) Horizontal cells in the marsupial retina. Soc Neurosci Abstr 17:559.

Honrubia FM, Elliot JH (1969) Horizontal cell of the mammal retina. Arch Ophthalmol 82:98-104.

Hsu SM, Raine L, Fanger H (1981) Use of avidin-biotin peroxidase complex $(\mathrm{ABC})$ in immunoperoxidase techniques. J Histochem Cytochem 29:577-580.

Jacobs GH, Neitz J (1986) Spcctral mcchanisms and color vision in the tree shrew (Tupaia belangeri). Vision Res 26:291-298.

Kolb H (1974) The connections between horizontal cells and photoreceptors in the retina of the cat: electron microscopy of Golgi preparations. J Comp Neurol 155:1-14.

Kolb $H$ (1977) The organization of the outer plexiform layer in the retina of the cat: electron microscopic observations. J Neurocytol 6:131-153.

Kolb H (1991) Anatomical pathways for color vision in the human retina. Vis Neurosci 7:61-74.

Kolb H, Ahnelt PK (1992) Color connectivity of human horizontal cells. Exp Eyc Res 55 [Suppl 1]:S.239.

Kolb H, Mariani A, Gallego A (1980) A second type of horizontal cell in the monkey retina. J Comp Neurol 189:31-44.

Kolb H, Linberg KA, Fisher SK (1992) Neurons of the human retina: a Golgi study. J Comp Neurol 318:147-187.

Maranto AR (1982) Neuronal mapping: a photooxidation reaction makes Lucifer yellow useful for electron microscopy. Science 217: 953-955.

Mariani AP (1985) Multiaxonal horizontal cells in the retina of the tree shrew, Tupaia glis. J Comp Neurol 233:553-563.

Müller B, Peichl L (1989) Topography of cones and rods in the tree shrew retina. J Comp Neurol 282:581-594.

Müller B, Peichl L (1991a) Rod bipolar cells in the cone-dominated retina of the tree shrew Tupaia belangeri. Vis Neurosci 6:629-639.

Müller B, Peichl L (1991b) Morphology and distribution of catecholaminergic amacrine cells in the cone-dominated tree shrew retina. J Comp Neurol 308:91-102.

Müller B, Peichl L, De Grip WJ, Gery I, Korf H-W (1989) Opsinand S-antigen-like immunoreactions in photoreceptors of the tree shrew retina. Invest Ophthalmol Vis Sci 30:530-535.

Peichl L, González-Soriano J (1993) Unexpected presence of neurofilaments in axon-bearing horizontal cells of the mammalian retina. J. Neurosci, in press.

Peichl L, Müller B (1991) Horizontal cells in the cone-dominated retina of the tree shrew. Soc Neurosci Abstr 17:13.

Peichl L, Buhl EH, Boycott BB (1987a) Alpha ganglion cells in the rabbit retina. J Comp Neurol 263:25-41.

Peichl L, Ott H, Boycott BB (1987b) Alpha ganglion cells in mammalian retinae. Proc R Soc Lond [Biol] 231:169-197.

Petry HM, Hárosi FI (1990) Visual pigments of the tree shrew (Tupaia belangeri) and greater galago (Galago crassicaudatus): a microspectrometric investigation. Vision Res 30:839-851.

Ramon y Cajal S (1893) La rétine des vertébrés. Cellule 9:119-257.

Raviola E, Dacheux RF (1990) Axonless horizontal cells of the rabbit retina: synaptic connections and origin of the rod aftereffect. J Neurocytol 19:731-736. 
Raviola E, Gilula NB (1975) Intermembrane organization of specialized contacts in the outer plexiform layer of the retina. J Cell Biol 65:192-222.

Reichenbach A, Wohlrab F (1983) Horizontal cells of the rabbit retina: some quantitative properties revealed by selective staining. Z Mikrosk Anat Forsch 97:240-244.

Robinson SR (1991) Development of the mammalian retina. In: Vision and visual dysfunction (Cronly-Dillon JR, ed), Vol 3, Neuroanatomy of the visual pathways and their development (Dreher B, Robinson SR, eds), pp 69-128. London: Macmillan.

Sandell JH, Masland RH (1988) Photoconversion of some fluorescent markers to a diaminobenzidine product. I Histochem Cytochem 36: $555-559$.

Silveira LCL, Yamada ES, Picanço-Diniz CW (1989) Displaced horizontal cells and biplexiform horizontal cells in the mammalian retina. Vis Neurosci 3:483-488.

Tauchi M, Masland RH (1984) The shape and arrangement of the cholinergic neurons in the rabbit retina. Proc R Soc Lond [Biol] 223: 101-119.

Vaney DI (1991) Many diverse types of retina neurons show tracer coupling when injected with biocytin or Neurobiotin. Neurosci Lett 125:187-190.

Vaney DI, Peichl L, Boycott BB (1981) Matching populations of amacrine cells in the inner nuclear and ganglion cell layers of the rabbit retina. J Comp Neurol 199:373-391.

Vickers JC, Costa M (1992) The neurofilament triplet is present in distinct subpopulations of neurons in the central nervous system of the guinea pig. Neuroscience 49:73-100.
Wässle H, Riemann HJ (1978) The mosaic of nerve cells in the mammalian retina. Proc R Soc Lond [Biol] 200:441-461.

Wässle H, Boycott BB, Peichl L (1978a) Receptor contacts of horizontal cells in the retina of the domestic cat. Proc R Soc Lond [Biol] 203:247-267.

Wässle H, Peichl L, Boycott BB (1978b) Topography of horizontal cells in the retina of the domestic cat. Proc R Soc Lond [Biol] 203: 269-291.

Wässle H, Peichl L, Boycott BB (1981) Dendritic territories of cat retinal ganglion cells. Nature 292:344-345.

Wässle H, Boycott BB, Röhrenbeck J (1989) Horizontal cells in the monkey retina: cone connections and dendritic network. Eur J Neurosci 1:421-435.

West RW (1978) Bipolar and horizontal cells of the gray squirrel retina: Golgi morphology and receptor connections. Vision Res 18:129-136.

West RW, Dowling JE (1975) Anatomical evidence for cone and rodlike receptors in the gray squirrel, ground squirrel, and prairie dog retinas. J Comp Neurol 159:439-460.

Wouterlood FG, Jorritsma-Byham B, Goede PH (1990) Combination of anterograde tracing with Phaseolus vulgaris-leucoagglutinin, retrograde fluorescent tracing and fixed-slice intracellular injection of Lucifer yellow. J Neurosci Methods 33:207-217.

Yamada ES, Silveira LCL, Coimbra AJF (1992) Topography of A-type horizontal cells in the retina of the capybara. Braz J Med Biol Res 25:619-632. 